\title{
A multi-MHz single-shot data acquisition scheme with high dynamic range: pump-probe $X$-ray experiments at synchrotrons
}

Alexander Britz, Tadesse A. Assefa, Andreas Galler, Wojciech Gawelda, Michael Diez, Peter Zalden, Dmitry Khakhulin, Bruno Fernandes, Patrick Gessler, Hamed Sotoudi Namin, Andreas Beckmann, Manuel Harder, Hasan Yavaş and Christian Bressler

J. Synchrotron Rad. (2016). 23, 1409-1423 
JOURNAL OF

SYNCHROTRON

RADIATION

ISSN 1600-5775

Received 24 March 2016

Accepted 4 August 2016

Edited by G. Grübel, HASYLAB at DESY, Germany

Keywords: time-resolved X-ray absorption spectroscopy; data acquisition instrumentation;

ultrafast detection; multi-photon counting.

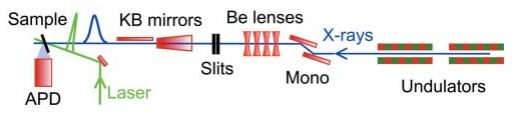

\section{A multi-MHz single-shot data acquisition scheme with high dynamic range: pump-probe $X$-ray experiments at synchrotrons}

\author{
Alexander Britz, ${ }^{\mathrm{a}, \mathrm{b} *}$ Tadesse A. Assefa, ${ }^{\mathrm{a}}$ Andreas Galler, ${ }^{\mathrm{a} *}$ Wojciech Gawelda, ${ }^{\mathrm{a}, \mathrm{c} *}$ \\ Michael Diez, ${ }^{\text {a,b }}$ Peter Zalden, ${ }^{\text {a,b }}$ Dmitry Khakhulin, ${ }^{\text {a,b }}$ Bruno Fernandes, ${ }^{a}$ \\ Patrick Gessler, ${ }^{a}$ Hamed Sotoudi Namin, ${ }^{a}$ Andreas Beckmann, ${ }^{a}$ Manuel Harder, ${ }^{d}$ \\ Hasan Yavaș $^{\mathrm{d} *}$ and Christian Bressler ${ }^{\mathrm{a}, \mathrm{b}, \mathrm{e} *}$ \\ aE uropean XFEL, Holzkoppel 4, 22869 Schenefeld, Germany, ${ }^{\mathbf{b}}$ The Hamburg Centre for Ultrafast Imaging, University \\ of Hamburg, Luruper Chaussee 149, 22761 Hamburg, Germany, 'Institute of Physics, Jan Kochanowski University, \\ Świętokrzyska 15, Kielce 25-406, Poland, dDeutsches Elektronen-Synchrotron (PETRA III), Notkestraße 85, 22607 \\ Hamburg, Germany, and ' Department of Physics, Technical University of Denmark, Fysikvej 307, Kongens Lyngby 2800 , \\ Denmark. *Correspondence e-mail: alexander.britz@xfel.eu, andreas.galler@xfel.eu,wojciech.gawelda@xfel.eu, \\ hasan.yavas@desy.de,christian.bressler@xfel.eu
}

The technical implementation of a multi-MHz data acquisition scheme for laserX-ray pump-probe experiments with pulse limited temporal resolution (100 ps) is presented. Such techniques are very attractive to benefit from the highrepetition rates of $\mathrm{X}$-ray pulses delivered from advanced synchrotron radiation sources. Exploiting a synchronized 3.9 MHz laser excitation source, experiments in 60-bunch mode $(7.8 \mathrm{MHz})$ at beamline P01 of the PETRA III storage ring are performed. Hereby molecular systems in liquid solutions are excited by the pulsed laser source and the total X-ray fluorescence yield (TFY) from the sample is recorded using silicon avalanche photodiode detectors (APDs). The subsequent digitizer card samples the APD signal traces in $0.5 \mathrm{~ns}$ steps with 12 bit resolution. These traces are then processed to deliver an integrated value for each recorded single X-ray pulse intensity and sorted into bins according to whether the laser excited the sample or not. For each subgroup the recorded single-shot values are averaged over $\sim 10^{7}$ pulses to deliver a mean TFY value with its standard error for each data point, e.g. at a given X-ray probe energy. The sensitivity reaches down to the shot-noise limit, and signal-to-noise ratios approaching 1000 are achievable in only a few seconds collection time per data point. The dynamic range covers 100 photons pulse ${ }^{-1}$ and is only technically limited by the utilized APD.

\section{Introduction}

Pump-probe experiments using pulsed hard X-rays from synchrotron radiation (SR) sources are still a growing field, since the first proof-of-principle experiments were performed about 15 years ago with $1 \mathrm{kHz}$ amplified laser systems (Lindenberg et al., 2000; Wulff et al., 1997; Chen et al., 2001; Saes, Gawelda et al., 2003; Bressler \& Chergui, 2004; Schotte et $a l ., 2003)$. Hereby a pulsed optical laser source is synchronized to selected X-ray pulses at a beamline, and the light-induced changes of the sample are followed in 'real time' by changing the relative time delay between the laser pump and the X-ray probe pulses. In steady-state studies, structural and spectroscopic techniques like X-ray diffraction (XRD), X-ray diffuse scattering (XDS), X-ray absorption (XAS) and X-ray emission (XES) spectroscopies are broadly used to determine spinand electronic-states as well as geometric structures of mate- 
rials. These tools, when paired with a laser excitation source across the UV-IR spectral range, can deliver new observables when investigating the kinetics of evolving chemical reactions as compared with optical-only tools, and applications including photovoltaic compounds, photocatalysts and functional organometallic chromophores are now becoming feasible (Bressler \& Chergui, 2004; Canton et al., 2013; Smolentsev \& Sundström, 2015; Zhang et al., 2015; Bressler et al., 2014; Vankó et al., 2013; March et al., 2015).

Time-resolved (TR) XRD (Lindenberg et al., 2000; Wulff et al., 1997; Larsson et al., 1998; Heimann et al., 2001; Schotte et al., 2003), XDS (Neutze et al., 2001) and XAS (Chen et al., 2001; Saes, Gawelda et al., 2003; Bressler et al., 2001; Vankó et al., 2015; Gawelda et al., 2005) experiments have been quite successful on solvated chromophores in liquids by using freeflowing flat sheets (with typical thicknesses in the $0.1-0.5 \mathrm{~mm}$ range) intersected by the X-ray probe beam (with typically $0.1-0.3 \mathrm{~mm}$ X-ray beam diameters). Optical lasers providing sufficient pulse energies to excite a significant fraction of reactant molecules (typical concentrations in the 0.01-0.1 $\mathrm{M}$ range), over a typical sample volume governed by the X-ray probe beam size (of the order of $\mathrm{nL}$ ), required laser pulse energies right below the milli-Joule range (Bressler \& Chergui, 2004), e.g. as routinely delivered by amplified titanium:sapphire (Ti:Sa) laser systems at $1-10 \mathrm{kHz}$ repetition rates. Synchrotrons generate X-ray pulses at much higher repetition rates (on the order of several $\mathrm{MHz}$ ), causing a mismatch of more than three orders of magnitude in repetition rate between laser excitation and X-ray probe sources. In such a $\mathrm{kHz}$ pump-probe scheme one needs to secure synchronization between the laser and X-ray sources (Saes et al., 2004), but also establish appropriate gating schemes to record those few selected X-ray pulses, and both mechanical (Wulff et al., 1997) and electronic (Saes, Gawelda et al., 2003; Saes et al., 2004) solutions have been realised at $1 \mathrm{kHz}$ repetition rate. The recorded X-ray data thus suffer dramatically in signal quality, as compared with steady-state X-ray studies using the full (or thousand-fold larger) X-ray flux available, and this penalty results in excessive collection times (of the order of several hours) needed for moderate signal-to-noise ratios (S/N) (Saes, Gawelda et al., 2003; Vankó et al., 2010). In a pioneering early attempt, Stern et al. used a $272 \mathrm{kHz}$ Ti:Sa laser system synchronized to the APS storage ring to drive solid-amorphous phase transitions in Ge samples, which were probed via extended X-ray absorption fine-structure spectroscopy (EXAFS) with sub-nanosecond time resolution (Stern et al., 2005). Their laser system delivered $4 \mu \mathrm{J}$ at $800 \mathrm{~nm}$, which was sufficient to excite the solid Ge film. For chemical dynamics applications, one would need to reduce the illuminated spot size to well below $50 \mu \mathrm{m}$ diameter and increase the fundamental laser pulse energy to higher values, since for most photochemical reactions the optical pump wavelength lies in the UV-VIS range, which can be generated with nonlinear optical crystals at selected wavelengths with $10-50 \%$ efficiency from the IR fundamental.

With the advent of ultrafast high-repetition-rate amplified laser systems, which deliver rather high pulse intensities in the
IR (typically of the order of $10-30 \mu \mathrm{J}$, and currently reaching 100-200 $\mu \mathrm{J}$ ) at variable (and adjustable) repetition rates throughout the $0.1-25 \mathrm{MHz}$ range, the repetition rate mismatch to SR sources is largely overcome (Lima et al., 2011; March et al., 2011; Stebel et al., 2011; Navirian et al., 2012; Issenmann et al., 2013). Now the X-ray signal quality increases by much more than an order of magnitude for otherwise equal data collection times. Such $\mathrm{MHz}$ optical laser pump-X-ray probe experiments can now deliver $\mathrm{S} / \mathrm{N}$ values matching those of conventional static X-ray experiments. For TR experiments this leads to an unprecedented sensitivity in revealing accurate excited-state geometrical structures (Vankó et al., 2015). Furthermore, these high repetition rates now allow the TR methodology to be extended into more flux-hungry techniques, such as TR non-resonant XES (Vankó et al., 2010), resonant XES (resonant inelastic X-ray scattering, RIXS) (Vankó et al., 2013), and possibly even towards TR X-ray Raman spectroscopy (Bergmann et al., 2002, 2007; Fister et al., 2009; Krisch \& Sette, 2002; Sternemann et al., 2008; Sahle et al., 2015).

At $\mathrm{MHz}$ repetition rates one can still record the laserexcited and dark sample in rapid alternating sequence, but such a scheme requires appropriate electronic gating and recording schemes for the X-ray signal (as mechanical solutions do not exist). Fast $\mathrm{MHz}$ gating, recording and sorted averaging is laboratory standard for low signal content, i.e. for single-photon-counting (SPC) methods. This is done using, for example, scintillators or APDs in combination with gated constant fraction discriminators (CFD) to measure X-ray absorption spectroscopy (March et al., 2011; Vankó et al., 2015). The successful use of SPC techniques limits the useful pulse intensity on the detector to well below one photon per X-ray pulse in order to prevent pile-up artefacts due to multiphoton events, which are counted as single photons. To exploit not only high repetition rates but equally the large single X-ray pulse intensity available at third-generation synchrotrons, we have developed a TR XAS setup at PETRA III which permits recording X-ray intensities with suitable dynamic range using a Si-based APD, which is capable of measuring intensities from well below single photons up to, in principle, several thousand photons per pulse (or more) (Saes, Gawelda et al., 2003; Saes et al., 2004; Vankó et al., 2010). This setup can thus be also applied at intense XFEL sources, and the European XFEL will have similar repetition rates (albeit with much higher single pulse intensities) (Altarelli et al., 2006) as we experience today at SR sources, which underlines the need for dynamic range at $\mathrm{MHz}$ repetition rates.

This development opens up new possibilities at many SR sources, but it is useful to first verify the utility of high-repetition-rate experiments at each selected synchrotron. Table 1 compiles the capabilities of selected SR sources for TR experiments at $\mathrm{MHz}$ repetition rates. Hereby it becomes apparent that the SR sources with larger circumference $(0.8-$ $2.3 \mathrm{~km}$ ) have more to gain from high-repetition-rate lasers than the smaller SR sources (operating also at lower electron beam energies which are less favorable to produce hard 
Table 1

Overview of the electron bunch filling patterns at selected SR facilities together with their corresponding single bunch charges.

The product of the X-ray repetition rate $f_{\mathrm{SR}}$ and bunch charge $Q$ gives a measure of the useful flux for time-resolved measurements with a laser system matching that repetition rate. For comparison the last row contains the results for a $1 \mathrm{kHz}$ laser system.

\begin{tabular}{|c|c|c|c|}
\hline $\begin{array}{l}\text { Synchrotron / } \\
\text { filling pattern }\end{array}$ & $\begin{array}{l}\text { Repetition } \\
\text { rate, } f_{\mathrm{SR}} \\
(\mathrm{MHz})\end{array}$ & $\begin{array}{l}\text { Stored charge } \\
Q \text { per bunch } \\
\text { per } 10^{10} \mathrm{e}^{-}\end{array}$ & $\begin{array}{l}f_{\text {SR }} \times Q \\
(\sim \text { useful flux }) \\
\text { per } 10^{16} \mathrm{e}^{-} / \mathrm{s}\end{array}$ \\
\hline PETRA III / 40-bunch $\dagger$ & 5.204 & 12 & 62.4 \\
\hline PETRA III / 60-bunch $\dagger$ & 7.8 & 8 & 62.4 \\
\hline APS / 24-bunch $\ddagger$ & 6.5 & 9.8 & 63.7 \\
\hline APS / hybrid $\ddagger$ & 0.272 & 37 & 10.1 \\
\hline ESRF / 4-bunch§ & 1.42 & 17.6 & 25.0 \\
\hline ESRF / 16-bunch§ & 5.68 & 9.9 & 56.2 \\
\hline ESRF / hybrid§ & 0.355 & 7.0 & 2.5 \\
\hline Soleil / 8-bunch & 6.776 & 7.36 & 49.9 \\
\hline Soleil / hybrid $\Phi$ & 0.847 & 3.68 & 3.1 \\
\hline ALS / 2-bunch $\dagger \dagger$ & 3.05 & 7.1 & 21.3 \\
\hline ALS / hybrid $+\dagger$ & 1.52 & 2.4 & 3.6 \\
\hline KEK & 0.794 & 3.9 & 3.1 \\
\hline SLS / hybrid $\$$ * & 1.04 & 1.2 & 1.2 \\
\hline SLS / kHz $\ddagger \ddagger$ & 0.001 & 1.2 & 0.0012 \\
\hline
\end{tabular}

$\dagger$ PETRA III (2015). \$ Borland et al. (2010). § ESRF (2015). @ Soleil (2015). †† ALS (2015). †े Saes, Gawelda et al. (2003), Saes et al. (2004).

$\mathrm{X}$-radiation). High-repetition-rate laser systems with sufficient pulse energies in the 1-10 $\mathrm{MHz}$ range are thus better suited at the larger SR sources: in Table 1 the normalized factor (i.e. useful X-ray flux) provides a comparison between the potential capabilities between different SR sources. However, this comparison does not take into account the (actually very different!) individual beamline specifications available at each synchrotron, but should serve as a guide to the eye for the available potential for TR experiments at each selected facility, and for each filling pattern reported in Table 1. A complete comparison between different beamlines in the hard $\mathrm{X}$-ray domain is beyond the scope of this work, and some changes (in ranking) are surely to be expected. Table 1 thus merely compares the principle capabilities of each facility based only on the stored electron beam properties. Nevertheless, this comparison can be used as a very useful starting point, from which individual beamlines at these facilities may compare their capabilities for TR experiments exploiting hard $\mathrm{X}$-rays in a pump-probe scheme, provided a laser system matching each SR repetition rate is available.

The table ranks PETRA III, APS, ESRF and Soleil (in its eight-bunch mode operation) well above the other synchrotrons. We refrained from including more exotic patterns permitting higher time resolution, e.g. low-alpha mode at BESSY-II and ANKA (Feikes et al., 2009; Ibrahimkutty et al., 2011), the use of X-ray streak cameras, and sliced femtosecond X-rays generated at ALS (Lindenberg et al., 2000), BESSY-II (Stamm et al., 2007) and SLS (Bressler et al., 2009), since these deliver X-ray fluxes orders of magnitude lower than considered in the present work with $\mathrm{MHz}$ repetition rates. For comparison reasons the conditions for $1 \mathrm{kHz}$ experiments at SLS are listed at the bottom of Table 1, emphasizing the dramatic boost in signal quality when performing pump-probe experiments at $\mathrm{MHz}$ repetition rates. Success of this avenue requires a sufficient amount of sample molecules to be excited in the X-ray probed volume, or laser pulse energies (at the selected UV-Vis wavelength) of the order of a few $\mu \mathrm{J}$, when laser and X-ray spot sizes of $<50 \mu \mathrm{m}$ can be realised at the beamline.

\section{Experimental approach for implementing $\mathrm{MHz}$ pump-probe experiments in the hard X-ray domain}

Time-resolved (pump-probe) measurements at synchrotron radiation sources benefit enormously when the repetition rate of the laser system matches that of the delivered X-ray pulses. However, in practice, there are limits to how much the optical laser repetition rate can be increased, either due to the time scale of the investigated reaction or due to conditions resulting in repeatedly striking the same sample volume, before it has been moved out of the probe volume. In the following we describe the implementation of the required instrumentation at beamline P01 at PETRA III for repetition rates from $0.13 \mathrm{MHz}$ (single-bunch round-trip frequency) up to $7.8 \mathrm{MHz}$ available in 60-bunch mode. Our data acquisition (DAQ) scheme was also applied at beamline P11 of PETRA III at $0.13 \mathrm{MHz}$ probe repetition rates for experiments using a $65 \mathrm{kHz}$ laser system (Goeries et al., 2016), but could also operate reliably at even higher repetition rates towards the inverse pulse width of typical electrical photodiode signals $(\sim 30 \mathrm{MHz})$.

\subsection{The PETRA III SR source for pump-probe studies}

The PETRA III electron storage ring has a circumference of $2304 \mathrm{~m}$, its RF-accelerating cavities operate at $\sim 500 \mathrm{MHz}$, generating 3840 of the so-called buckets with 2 ns separation, which can each support stable storage of electron charges. In practice, only 40, 60 or 960 buckets are filled with electrons yielding bunch separations of $192 \mathrm{~ns}, 128 \mathrm{~ns}$ and $8 \mathrm{~ns}$, respectively. The total current of the ring is kept constant at $100.5 \mathrm{~mA}$ within $\pm 0.5 \%$ via relatively frequent (every $1-$ $2 \mathrm{~min}$ ) injections of electrons, in this so-called top-up operation mode. For the TR (pump-probe) measurements described in this work, only 40- and 60-bunch modes are used. In 60-bunch mode, where the X-ray pulse-repetition rate is $7.8 \mathrm{MHz}$, every other (i.e. every second) X-ray pulse records the laser-excited sample when the laser is tuned to half of its repetition rate. The high stability of the X-ray flux allows for accurate comparison (normalization) of the recorded intensities for the dark and laser-illuminated sample.

One issue about top-up operation of the synchrotron concerns fluctuating X-ray intensities on the sample during the injection process itself, which lasts for a few seconds. These top-up-induced fluctuations occur on a slow time scale (much slower than $1 \mathrm{kHz}$ ), so rapid recording of alternate intensities is not at all hampered, and transient signals (i.e. normalized laser-on and laser-off X-ray signals) do not detect the injection process (apart from subtly larger error bars; more details below in \$3.4). However, each of the 60 stored electron 
bunches is not equally refilled in a controlled fashion, and this leads therefore to small step-wise changes in the recorded transient signal, when, for example, the top-up mode preferentially filled into some of the even buckets. We have previously circumvented this (though weak) issue by synchronizing the laser to a repetition rate which is not an integer of the single-bunch frequency of the storage ring (e.g. every fifth pulse at APS in 24-bunch mode) (Vankó et al., 2015), which eliminates this artefact conveniently, since the laser-excited and laser-off X-ray signals are equally generated and averaged over every single pulse inside the storage ring. Another way to eliminate this artefact is to simply use a gated $I_{0}$ detector for single-shot intensity normalization, which has been applied in this work.

\subsection{The Dynamics beamline P01}

The experiments were performed at the Dynamics beamline, P01, of PETRA III at DESY in Hamburg (Wille et al., 2010). This beamline is dedicated to nuclear resonant scattering measurements in experimental hutch 1 (EH1) (Röhlsberger et al., 2012), to inelastic X-ray scattering (IXS) in EH2 (Ketenoglu et al., 2015), and towards laser-driven melting of geologically relevant samples (e.g. silicate melts with a cw/ns heating laser) (Sternemann et al., 2008). EH2 has recently upgraded its capabilities to permit laser-driven pump-probe experiments on solvated samples together with our adjustable 0.1-10 MHz femtosecond laser system, the latter having already passed its proof-of-principle test at ESRF (Vankó et $a l ., 2015)$. The present work concerns experiments at $7.8 \mathrm{MHz}$ repetition rate, thus to the best of our knowledge at the highest repetition rate ever applied for TR XAS measurements at any SR source worldwide.

A schematic of the beamline setup used in these experiments is shown in Fig. 1. X-ray pulses are created when electron bunches pass through two $5 \mathrm{~m}$-long undulators. The $\mathrm{X}$-ray pulses are monochromated to $\Delta E / E=1.4 \times 10^{-4}$ with a liquid- $\mathrm{N}_{2}$-cooled $\mathrm{Si}(111)$ fixed-exit double-crystal monochromator (DCM). Beryllium lenses after the monochromator are used to pre-focus the beam to match the acceptance of the Kirkpatrick-Baez (KB) mirrors, which subsequently focus the beam on the sample to a size of about $15 \mu \mathrm{m} \times 30 \mu \mathrm{m}(\mathrm{V} \times$ $\mathrm{H})$. The total number of monochromatic photons at the sample position is of the order of $10^{13} \mathrm{~s}^{-1}$.

\subsection{Liquid-jet flat sheet target}

The experimental setup described here has been developed with the aim of investigating photoexcited solvated molecular systems, and extends our previously implemented setups (Saes, Bressler et al., 2003; Saes et al., 2004) into the $\mathrm{MHz}$ repetition rate range, similar to developments at other SR sources (Lima et al., 2011; March et al., 2011). It is based on using flat sheet liquid jets generated through rectangularshaped nozzles (Victor Kyburz AG) with selected thicknesses in the 0.1 to $0.3 \mathrm{~mm}$ range (and widths of about $6-8 \mathrm{~mm}$ ).

We generally use the $0.1 \mathrm{~mm}$-thick nozzle flowing the liquid downwards at an adjustable speed in the range $0.5-30 \mathrm{~m} \mathrm{~s}^{-1}$ with either a (specially coated, thus chemically resistant) gear pump or with a (slower) peristaltic pump with Teflon tubing. Stable flat sheets were obtained with both pumps, but the micro annular gear pump (mzr-11508X1, HNP Mikrosysteme) proved to operate reliably with various solvents covering a fairly broad range of viscosities. The thin film jet is usually rotated around the vertical axis to about $45^{\circ}$ with respect to the X-ray beam direction. This permits XAS to be recorded in TFY mode with its detector placed sideways from the sample [and/or to disperse the sideways-emitted X-ray fluorescence with a secondary crystal-based bent crystal arrangement to record the X-ray emission spectra (Haldrup et al., 2012)].

\subsection{Multi-MHz fiber amplifier laser system}

The high-repetition-rate laser consists of a bulk oscillator (t-Pulse, Amplitude Systèmes) (Zaouter et al., 2008), synchronized and locked to the RF of the storage ring, which seeds a high-energy fiber amplifier (Tangerine 20W, Amplitude Systèmes). The $\mathrm{Yb}$ :KYW bulk oscillator generates a stable train of $200 \mathrm{fs}$ mode-locked pulses at $62.5 \mathrm{MHz}$ with an average power of $1.5 \mathrm{~W}$. The laser cavity contains a set of actuators that are used to precisely lock the frequency of the laser cavity to the PETRA III RF frequency and reduce the timing jitter to less than 1 ps (the synchronization scheme is described in \$2.7). A small fraction of the average power is coupled into a single-mode polarization-conserving fiber and seeds the high-power fiber amplifier. Using chirped pulse amplification together with a state-of-the-art single-mode rodtype fiber (which mitigates the accumulation of non-linearities during propagation and amplification in the core of the fiber amplifier), a maximum pulse energy of $60 \mu \mathrm{J}$ (and $300 \mathrm{fs}$ pulse width) is produced at $400 \mathrm{kHz}$. The repetition rate of the output pulses can be changed from below $400 \mathrm{kHz}$ to 15.6 MHz via an acousto-optical modulator (AOM) based pulse picker situated upstream in the amplifier chain. The output power and all spatial beam parameters remain constant at all selectable repetition rates ensuring the production of $300 \mathrm{fs} / 6 \mu \mathrm{J}$ pulses at 3.9 $\mathrm{MHz}$ and maintaining the pointing stability. The laser wavelength of $1030 \mathrm{~nm}$ can be converted to $515 \mathrm{~nm}$, $343.3 \mathrm{~nm}$ and $257.5 \mathrm{~nm}$ by second- $(\mathrm{SH})$,
Figure 1

Sketch of the dynamics beamline P01 of PETRA III consisting of $2 \times 5 \mathrm{~m}$-long undulators to generate X-rays, a $\mathrm{Si}(111)$ double-crystal monochromator, a stack of beryllium prefocusing lenses followed by slits and KB mirrors for micro-focusing. 
third- (TH) and fourth-harmonic (FH) generation crystals, respectively. The optical laser beam is then guided to and focused on the liquid jet; the losses from the amplifier output to the sample position can reach $50 \%$. The beam size at the position of the jet is on the order of $50 \mu \mathrm{m} \times 50 \mu \mathrm{m}$, thus slightly larger than the X-ray spot size of $15 \mu \mathrm{m} \times 30 \mu \mathrm{m}$. The conversion efficiencies, which we obtained, amount to $\sim 36 \%$, $\sim 9.6 \%$ and $\sim 4.6 \%$ at $400 \mathrm{kHz}$ repetition rate; this leads to maximum pulse energies at the sample position of $\sim 30 \mu \mathrm{J}$, $\sim 11 \mu \mathrm{J}, \sim 2.9 \mu \mathrm{J}$ and $\sim 1.4 \mu \mathrm{J}$ for fundamental, $\mathrm{SH}, \mathrm{TH}$ and $\mathrm{FH}$, respectively. For example, at $257.5 \mathrm{~nm}$ we can adjust the excitation intensities with this system (using a half-wave plate and a polarizer) up to $240 \mathrm{GW} \mathrm{cm}^{-2}$.

\subsection{Spatial and temporal overlap of X-ray and laser beams}

The X-ray and laser beams are overlapped in a nearcollinear geometry. The angle between both beams is as small as possible $\left(5-20^{\circ}\right.$ depending on setup; here we used $\left.\sim 10^{\circ}\right)$, to ensure a long longitudinal range with good overlap. Both beams are spatially overlapped using tungsten pinholes with different diameters between $25 \mu \mathrm{m}$ and $100 \mu \mathrm{m}$. To achieve temporal overlap, a fast photodiode (Opto Diode Corp, Model AXUVHS5) with a $700 \mathrm{ps}$ rise-time on a fast oscilloscope (LeCroy WaveRunner 640Zi with $4 \mathrm{GHz}$ analog bandwidth and $20 \mathrm{GS} \mathrm{s}^{-1}$ acquisition) are used to record traces of laser and X-ray pulses. The half-rise position of each pulse and thus their time separation can be determined with an accuracy of around 100 ps. Eventually, the actual pump-probe signal is used to determine time-zero accurately. Adjusting the time delay between both laser and X-ray pulses is described below in $\$ 2.7$.

\subsection{X-ray fluorescence detection strategy}

The total X-ray fluorescence yield (TFY) from the liquid jet is detected with an APD (Baron et al., 2006) system, consisting of an APD head combined with a fast preamplifier (APD0008, FMB Oxford) and a control/power supply unit (ACE BOX, FMB Oxford). The APD head ( $10 \mathrm{~mm} \times 10 \mathrm{~mm}$ active surface area) is placed about $20 \mathrm{~mm}$ away from the sample perpendicular to the X-ray propagation direction (or along the linear polarization axis of the X-ray beam), to minimize the detection of elastic scattering from the solvent. In this geometry the detector covers a solid angle of $0.25 \mathrm{sr}$ (or $2 \%$ of $4 \pi$ ). A second APD system can be used to measure the TFY of a lower- $Z$ material, e.g. a $\mathrm{Mn}$ foil (in the case of Fe-containing samples), located downstream from the sample position. Although located behind the actual liquid sample, we exploit this device as a reliable indicator of the incident intensity $\left(I_{0}\right)$, especially concerning the frequent intensity fluctuations due to top-up injections: the X-rays impinging on the sample \{here: $20 \mathrm{mM}$ of aqueous $\left[\mathrm{Fe}(\mathrm{bpy})_{3}\right]^{2+}$ \} penetrate through the entire length of the sample of about $0.14 \mathrm{~mm}$ (corresponding to the $0.1 \mathrm{~mm}$ thick jet rotated to $45^{\circ}$ ), and this results in an attenuation by $18 \%$ due to the solvent alone (which is very constant at all energies used around the $\mathrm{Fe} K$-edge). The solute contributes to $0.1 \%$ below and to $0.6 \%$ above the $\mathrm{Fe} K$-edge (with an excited-state fraction $f=0$ for the stationary sample) and the $\mathrm{X}$-ray transmission through the liquid flat sheet jet $T_{\mathrm{jet}}$ is given by the ratio of intensities before and after the sample via (Bressler \& Chergui, 2004)

$$
\begin{aligned}
T_{\text {jet }}= & \left(I_{1} / I_{0}\right)=\exp \left(-n_{\text {sol }} \sigma_{\text {sol }} d\right) \exp \left(-n_{\text {sam }} \sigma_{\text {rest }} d\right) \\
& \times \exp \left[-(1-f) n_{\text {sam }} \sigma_{\mathrm{GS}} d\right] \exp \left(-f n_{\mathrm{sam}} \sigma_{\mathrm{ES}} d\right) .
\end{aligned}
$$

Here $n_{\text {sol }}$ and $n_{\text {sam }}$ are the solvent and sample concentrations (in particles $\mathrm{mm}^{-3}$ ), respectively, $\sigma_{\mathrm{sol}}, \sigma_{\mathrm{GS}}, \sigma_{\mathrm{ES}}$ and $\sigma_{\text {rest }}$ are the X-ray (thus energy-dependent) absorption cross sections of the solvent and solute molecules in their ground (GS) and excited states (ES), and $\sigma_{\text {rest }}$ that of all other elements within the solute molecule (including counterions), respectively. The laser power (given in number of laser photons per pulse $N_{0}^{\mathrm{ph}}$ ) enters via the photoexcitation yield of the excited solute molecules via $f=f\left(n_{\mathrm{sam}}, N_{0}^{\mathrm{ph}}, \sigma_{\mathrm{opt}}\right)$, with $\sigma_{\mathrm{opt}}$ being the optical absorption cross section of the solute molecule at the selected laser wavelength (for the current estimate of sample transmission we use $f=0$, but we include it later for the analysis of the TR signals), the incident X-ray intensity is $I_{0}$. Thus the $\mathrm{X}$-ray transmission through the sample to the second foil is $81.9 \%$ below and $81.4 \%$ above the $\mathrm{Fe} K$-edge, and the difference between both transmission values is thus $7 \times 10^{-3}$, which would only become distinguishable (within Poisson statistics) if the collected intensity is $\gg 10^{4}$ (we typically collect $\sim 10^{8}$ photons $\mathrm{s}^{-1}$ ).

Finally, in this setup we record an X-ray fluorescence signal, e.g. from the Mn foil downstream of the sample, of

$$
I_{\mathrm{Mn}}=I_{0} T_{\text {jet }}\left(1-T_{\mathrm{Mn}}\right) \varepsilon_{\mathrm{Mn}} \Omega_{\mathrm{det}} \varphi_{\mathrm{det}, \mathrm{Mn}},
$$

thus correcting the incident intensity $I_{0}$ for the transmission $T_{\text {jet }}$ through the liquid sample, the absorption $\left(1-T_{\mathrm{Mn}}\right)$ in the Mn foil, the X-ray emission quantum yield $\varepsilon_{\mathrm{Mn}}$, the covered X-ray emission solid angle $\Omega_{\text {det }}$ to the detector and the detector efficiency $\varphi_{\operatorname{det}, M n}$. This yields a fluorescence count rate of $>50$ photons under our experimental conditions with an incident flux of $10^{13}$ photons $\mathrm{s}^{-1}$ (corresponding to about $10^{6}$ photons pulse $^{-1}$ incident on the liquid sample). The fluorescence count rate $I_{\mathrm{Mn}}$ is adjusted to at least the count rate of the X-ray fluorescence signal $I_{\mathrm{TFY}}$ from the sample itself to ensure that normalization (to remove top-up injection artefacts) does not spoil the overall error of this measurement. When measuring with less than $10^{4}$ photons pulse ${ }^{-1}$ the small variation of $T_{\text {jet }}$ (below/above the edge) does not change the count rate for $I_{\mathrm{Mn}}$ significantly, and can thus even serve for (rough) single-shot normalization for the incident intensity $I_{0}$. Of course, when collecting several millions of shots this deviation becomes measurable (see $\$ 3.4$ later), but the goal here is to normalize to the top-up injection process on a shotby-shot basis, which increases certain X-ray pulses by up to a few percent (and averages over all bunches within a round trip) to the limiting set value of $1 \%$ top-up injection.

The actual setup aims to measure TR XAS of photoexcited samples in the hard X-ray regime in TFY mode. This is done by scanning the incident X-ray energy with the primary DCM and recording the TFY with the sideways-placed APD (Fig. 2). 
The number of total fluorescence photons $I_{\mathrm{TFY}}$ is given by the number $I_{\mathrm{abs}}$ of absorbed X-ray photons by the solute alone, by the total fluorescence yield $\varepsilon_{\text {total }}$, the covered solid angle $\Omega_{\mathrm{APD}}$ and detection efficiency $\varphi_{\text {det,I1 }}$ of the APD as scaling factors via (Jaklevic et al., 1977)

$$
I_{\mathrm{TFY}}=I_{\mathrm{abs}} \varepsilon_{\mathrm{total}} \Omega_{\mathrm{APD}} \varphi_{\mathrm{det}, \mathrm{I} 1},
$$

with

$$
\begin{aligned}
I_{\mathrm{abs}}= & I_{0}\left(1-T_{\mathrm{jet}}\right) \\
& \times \frac{(1-f) n_{\mathrm{sam}} \sigma_{\mathrm{GS}}+f n_{\mathrm{sam}} \sigma_{\mathrm{ES}}}{n_{\mathrm{sol}} \sigma_{\mathrm{sol}}+n_{\mathrm{sam}} \sigma_{\mathrm{rest}}+(1-f) n_{\mathrm{sam}} \sigma_{\mathrm{GS}}+f n_{\mathrm{sam}} \sigma_{\mathrm{ES}}} .
\end{aligned}
$$

To roughly estimate the fluorescence signal per X-ray pulse of a $20 \mathrm{~m} M \mathrm{Fe}$ compound in aqueous solution in a $100 \mu \mathrm{m}$ jet tilted to $45^{\circ}$ we assume an incident X-ray flux of $10^{6}$ photons pulse $^{-1}$ at photon energies just above the Fe $K$-edge. About 5000 photons are absorbed at the Fe $K$-edge (thus $0.5 \%$ of the incident ones, which can emit $K$ radiation), which results, together with the total fluorescence efficiency of Fe $\varepsilon_{\text {total }} \approx$ $\varepsilon_{K \alpha}+\varepsilon_{K \beta} \approx 36 \%$ (Thompson et al., 2009), the 0.25 sr covered by the APD and the $\sim 95 \%$ detector efficiency of the APD at $6 \mathrm{keV}$ (FMB Oxford, 2009), in an expected flux of about 35 photons pulse ${ }^{-1}$.

In the case of relatively thin samples $\left[n_{\mathrm{sol}} \sigma_{\text {sol }}+n_{\mathrm{sam}} \sigma_{\text {rest }}+\right.$ $\left.(1-f) n_{\mathrm{sam}} \sigma_{\mathrm{GS}}+f n_{\mathrm{sam}} \sigma_{\mathrm{ES}} \ll 1\right]$ the exponential term in equation (1) can be simplified and we can approximate $I_{\mathrm{abs}} \approx$ $I_{0} d n_{\mathrm{sam}}\left[(1-f) \sigma_{\mathrm{GS}}+f \sigma_{\mathrm{ES}}\right]$ (Jaklevic et al., 1977). Using this, we can provide an estimate for the expected pump-probe transient signal $S=I_{\mathrm{TFY}, \mathrm{ON}}-I_{\mathrm{TFY}, \mathrm{OFF}}=I_{\mathrm{TFY}}(f)-$ $I_{\mathrm{TFY}}(f=0)$, which is given by the normalized difference of the total fluorescence yield $I_{\mathrm{TFY}, \mathrm{ON}}$ with and $I_{\mathrm{TFY}, \mathrm{OFF}}$ without laser excitation, as

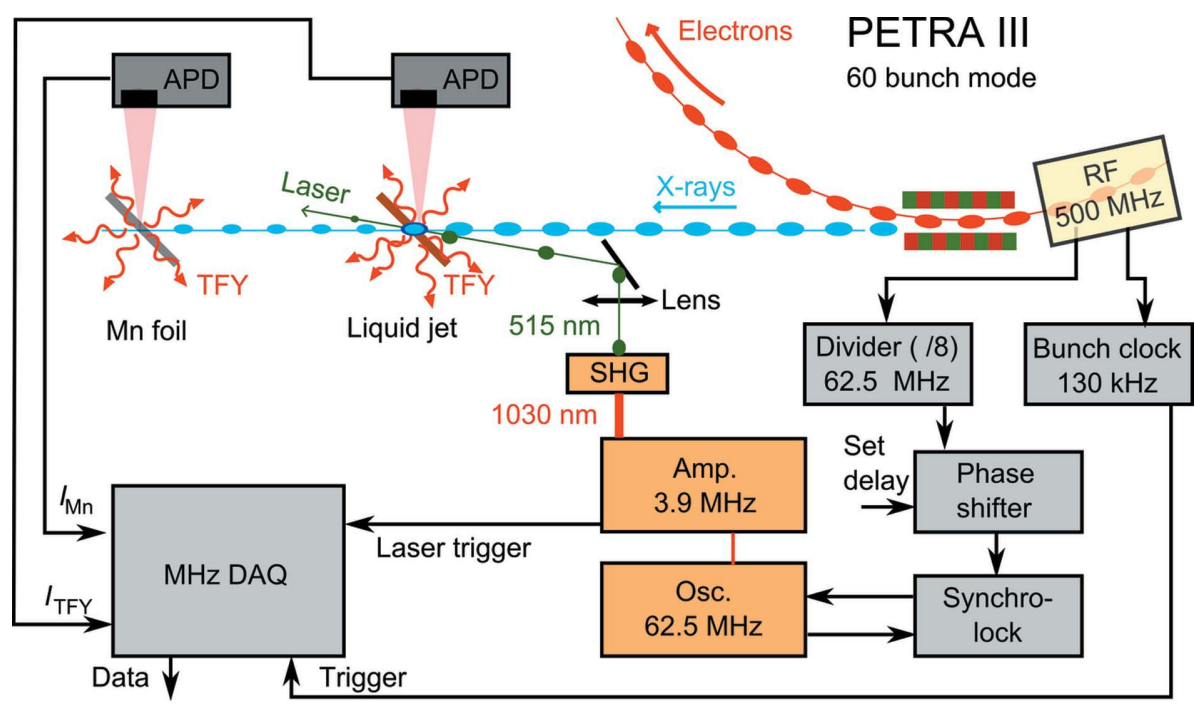

Figure 2

Sketch of the experimental setup at the dynamics beamline P01 of PETRA III (here: in 60-bunch mode delivering X-ray pulses at 7.8 MHz), including a fiber amplifier laser system synchronized to the RF frequency of the storage ring and our MHz DAQ system capable of digitizing and integrating the APD detector signal traces.

$$
S=f\left[\sigma_{\mathrm{ES}}-\sigma_{\mathrm{GS}}\right] n_{\mathrm{sam}} d I_{0} \varepsilon_{\mathrm{total}} \Omega_{\mathrm{APD}} \varphi_{\mathrm{det}, \mathrm{I} 1} .
$$

For the above-mentioned case the excitation yield $f$ is typically $10 \%$, while the X-ray absorption cross sections for the ground and excited species typically differ by less than $100 \%$ (in the XANES region, compared with the $K$-edge jump), thus we obtain for the transient $\mathrm{X}$-ray fluorescence signal a value of 3.5 photons pulse $\mathrm{e}^{-1}$ (on the static 35 photons pulse ${ }^{-1}$ ), or $10 \%$. When the expected pump-probe signal becomes smaller (e.g. in the EXAFS region or due to smaller differences in $\sigma$ or small $f$ ), it is therefore paramount to increase the statistics significantly, which the presented experimental DAQ scheme, in combination with a $\mathrm{MHz}$ laser system, provides.

\subsection{Synchronization and data acquisition strategy at $\mathrm{MHz}$ repetition rates}

The laser system is synchronized to the storage ring in the following way (Fig. 2). The RF signal from the storage ring (a $500 \mathrm{MHz}$ sinusoidal) is converted into a $62.5 \mathrm{MHz}$ trigger signal by a frequency divider (1/8). This trigger is sent over a phase shifter module before it enters a frequency mixer unit, where it is combined with the $62.5 \mathrm{MHz}$ signal from the laser oscillator to derive and actively correct for any phase variations. These phase variations between both signals cause a variation of the relative timing between the laser and X-ray pulses, and are minimized in the synchronization lock unit to maintain a reliable (constant) timing between laser and X-ray pulses. This is realised with a timing jitter much better than the laser-X-ray instrument response function which mainly consists of an X-ray pulse width of $\sim 100 \mathrm{ps}$ (Schröder et al., 2011) (see, for example, Fig. 9 later). In order to change the relative timing between laser and X-ray pulses the frequencydivided (1/8) RF signal is phase-shifted using an electronic phase shifter unit, so that the signal entering the synchronization lock unit leads to an adjustment of the laser oscillator frequency (via moving one of the end mirrors in the laser cavity), so that the output laser pulses exit at a slightly shifted time, until the desired time delay has been reached. Therefore, the phase shifter unit acts as a tool to control the relative laser-X-ray time delay. This is done by coarse and fine adjustment of the optical path length in the oscillator by translating one mirror with a servo motor and the second one with a piezo actuator. A proportional-integral-derivative (PID) controller in the synchronization lock unit is used to online correct timing jitter by controlling the piezo of one mirror. With the $62.5 \mathrm{MHz}$ of the RF signal, we calculate that a phase shift of $1^{\circ}$ results in a time shift of the laser pulses of 44.44 ps with respect to the X-ray pulses. The phase shifter unit is connected to the data acquisition 
$\mathrm{PC}$ in order to monitor and control the time delay while acquiring data during a scan.

The X-ray TFY signal generates APD signal traces that are fed into the DAQ system (a micro TCA based solution with high-speed digitizers; SP Devices). Each digitizer consists of four 12-bit analog-to-digital converters (ADCs) accompanied by a Field Programmable Gate Array (FPGA; Xilinx Virtex 6) for online data processing. In its standard configuration, this ADC is able to digitize the traces of our APD detectors at a sampling rate of $2 \mathrm{GS} \mathrm{s}^{-1}$. Alternatively, it is also possible to configure the digitizer in the so-called two-channel interleaved mode to increase the sampling rate to $4 \mathrm{GS} \mathrm{s}^{-1}$ channel $^{-1}$ (which reduces the number of available channels to two per ADC). The digitizer is synchronized to a sub-harmonic of the accelerating RF to ensure stable phase relations. In addition, a time-to-digital converter (TDC) firmware core has been implemented in the FPGA for precise measurement of the rising edge of the provided trigger relative to the sampling clock. The TDC implementation allows for an accuracy of about 42 ps RMS. A similar approach reported on a quadrant APD together with a commercially available ADC at an eightfold lower sampling rate (and no TDC implementation) to measure multi-photon events at $\mathrm{MHz}$ repetition rates (Reusch et al., 2014). Our large sampling rate has proven to be beneficial in order to extract precise integrated signal intensities. As the maximum peak-to-peak input signal to our ADC is limited to $800 \mathrm{mV}$, the APD signal must be attenuated accordingly when signal intensities exceed this limit.

The trigger and gating scheme for DAQ with the XFEL $\mathrm{MHz}$ DAQ is depicted in Fig. 3 and works as follows. The entire detection system is triggered by the so-called bunchclock, a device which generates trigger pulses either at the repetition rate of the X-ray pulses or at the round-trip frequency of a single bunch from the $500 \mathrm{MHz} \mathrm{RF}$ signal. In our scheme, a round-trip frequency of about $130 \mathrm{kHz}$ is used to trigger the data acquisition, even if the laser operates at higher repetition rates, i.e. 20 -fold (40 bunch) or 30-fold (60 bunch). The APD traces are sampled and processed for the duration of the following 40 or $60 \mathrm{X}$-ray pulses (following each trigger signal at $130 \mathrm{kHz}$ ), depending on the bunch mode of the experiment. The sampled traces can be displayed online to select regions of interest for (i) the background signal before the pulse and (ii) the X-ray pulse, respectively. An example of such a sampled single APD trace can be found

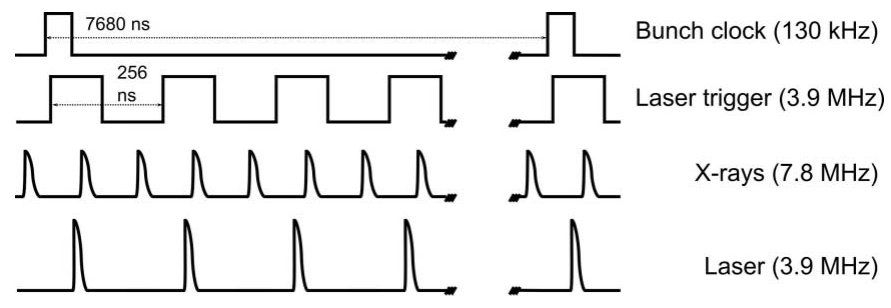

Figure 3

Example of the trigger and gating scheme of the MHz DAQ in 60-bunch mode of PETRA III, where the laser repetition rate is set to $3.9 \mathrm{MHz}$. In our experiments we mainly used 60-bunch mode, but 40-bunch mode is equally useful (for details see text). in Fig. 4(a). The following parameters are defined during operation and are applied to the system employing an integration algorithm: the starting point and total number of sampling points (i) of the background/baseline and (ii) of the APD signal trace (see Fig. 4a). The FPGA-based algorithm calculates the sum of the pulse and background samples and scales the background sum to be correctly removed from the pulse sum resulting in the single-shot detection signal $I_{\mathrm{TFY}}$. A second trigger, derived from a photodiode within the $\mathrm{MHz}$ laser amplifier, is used to distinguish between traces (i) right after laser excitation and (ii) those without prior laser excitation; these are rapidly sorted into $I_{\mathrm{TFY}, \mathrm{ON}}$ and $I_{\mathrm{TFY}, \mathrm{OFF}}$ for pumped and unpumped signals, respectively. Additionally,
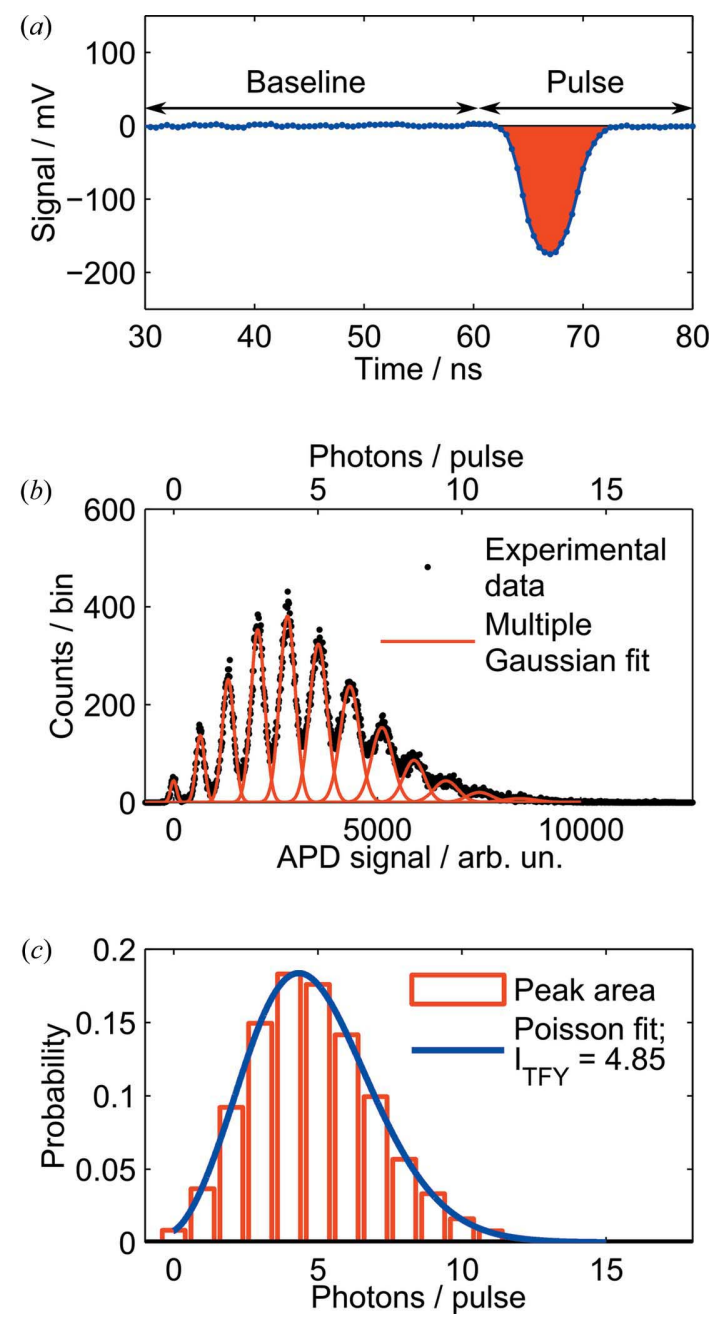

Figure 4

(a) A single X-ray induced APD signal trace sampled with $2 \mathrm{GS} \mathrm{s}^{-1}$. These are then processed to determine the baseline and the integrated signal area (indicated), delivering a measure of the X-ray intensity of the corresponding pulse. Here $\sim 100$ samples are used to extract the background and $\sim 70$ for the signal, delivering $\sim$ ten-fold more precise values than the standard deviation of $\sim 1.4 \mathrm{mV}$ of the baseline signal. (b) Measured pulse-height distribution of the integrated APD signal traces for $10^{5}$ single shots. The bottom ordinate denotes the raw signal amplitude per pulse, and the upper ordinate identifies the number of photons pulse ${ }^{-1}$. A sum of 12 Gaussians, each corresponding to integer photon numbers between 0 and 11, has been fitted. The integrated areas of each Gaussian, shown in (c), follow a Poisson distribution delivering a mean value of 4.85 photons per X-ray pulse in this measurement. 
some parameters are calculated online, such as, for example, mean values of $I_{\mathrm{TFY}, \mathrm{ON}}$ and $I_{\mathrm{TFY}, \mathrm{OFF}}$ and their respective standard deviations. In the current state of the MHz DAQ we are able to acquire, integrate, baseline correct and average up $\sim 6 \times 10^{6}$ pulses s $^{-1}$ in real time (neglecting $\sim 10 \%$ dead-time due to communication between beamline control PC and, for example, the X-ray monochromator motor controls, or the phase shifter mirror controls).

\section{Results: signal statistics and time-resolved XAS measurements}

In this section, first results obtained with the above-described setup are shown. These include tests of the linearity of the detector/DAQ system combination, a characterization of the detector signal statistics and benchmark TR XAS measurements of transition metal complexes with extremely high signal quality.

\subsection{Detector signal statistics}

To test the detector/DAQ combination we have measured the TFY from a $300 \mu \mathrm{m}$ liquid jet containing a $50 \mathrm{~m} M$ aqueous solution of $\mathrm{K}_{4}\left[\mathrm{Fe}(\mathrm{CN})_{6}\right]$. The total fluorescence from the iron atom consists of mainly $K_{\alpha}$ X-ray photons around $6.40 \mathrm{keV}$ and the weaker $K_{\beta}$ emission at $7.05 \mathrm{keV}$ [the ratio of fluorescence yield is $\varepsilon_{K \alpha} / \varepsilon_{K \beta} \simeq 150 / 17$, so $90 \%$ of the fluorescence mainly contains $K_{\alpha}$ photons (Thompson et al., 2009)]; the remaining valence-to-core emission we disregard here, since it is 500-fold times weaker than the $K_{\alpha}$ emission (Vankó et al., 2006). We have varied the APD bias voltage from $200 \mathrm{~V}$ up to $350 \mathrm{~V}$ (right below its break-down voltage) to adjust the internal APD gain, depending on the recorded X-ray flux. For calibration purposes the upstream beamline slits have been gradually closed to attenuate the incident X-ray intensity, and the incident flux on the sample was monitored with a PIN diode measuring scattered X-rays from a Kapton window downstream of the high-vacuum KB focusing mirror system (and before the sample). The recorded sample fluorescence signal for a collection of $10^{5}$ shots with attenuated beam reveals the expected Poisson statistics for an average singlepulse intensity of about 5 photons pulse ${ }^{-1}$ (Fig. 4b). Being mainly of statistical nature, the signals follow a Poisson distribution,

$$
P(\lambda, k)=\frac{\lambda^{k} \exp (-\lambda)}{k !} .
$$

Hereby $k$ corresponds to the number of photons detected in a single pulse with $\lambda$ being the mean value of photons detected after a large (towards infinite) number of acquired pulses; in our case $\lambda$ corresponds to the total fluorescence yield $I_{\mathrm{TFY}}$ extracted via equation (5) after, for example, $10^{5}$ acquired pulses (as shown later in \$3.2).

In the case of only a few photons striking the detector the discrete peaks representing one, two, three, etc. photon events are well separated (up to $\sim 10$ pulse $^{-1}$ ). This already allows for a very precise calibration from the integrated signal voltage to absolute number of photons. The broadening of each peak is due to effects in the amplification process in the APD itself, including avalanche gain noise and preamplifier noise, next to electronic noise, which can be best seen in the zero photon event (Fig. 4b). To separate the signals belonging to each integer number of photons a sum of Gaussian peaks has been fitted to the measured pulse height distribution (Fig. 4b), and the area of each single Gaussian is proportional to the number of events for this chosen number of photons. These Gaussian areas are then normalized to a total area of 1 , and a fit to a Poisson distribution [equation (5)] delivers the precise singlepulse intensity of $I_{\mathrm{TFY}}=4.85$ (Fig. $4 c$ ). For larger single-photon intensities (thus at higher incident flux), the Poisson distribution curve [blue trace in Fig. 4(c)] merges into a Gaussian distribution, and this already [via equation (5)] for singlepulse intensities around/above 10 photons pulse ${ }^{-1}$. In the case of a Gaussian distribution, where a clear separation of the discrete peaks is no longer present, the mean number of photons can still be precisely determined: for a shot-noiselimited measurement the standard deviation of the measured average signal $\lambda$ becomes $\sigma_{\mathrm{p}}=\sqrt{\lambda}$ and we can relate $I_{\mathrm{TFY}}$ to its experimentally determined standard deviation $\sigma$ via (Saes et al., 2004)

$$
\lambda=\left(\frac{\lambda}{\sigma_{\mathrm{p}}}\right)^{2} \geq\left(\frac{I_{\mathrm{TFY}}}{\sigma}\right)^{2}
$$

In the case of a purely shot-noise broadened distribution (neglecting all electronic noise), the greater-equals sign becomes an equals sign. An example of a pulse-height distribution of the detector signal with a mean signal corresponding to $I_{\mathrm{TFY}}=80$ photons [recorded at a bias voltage of $200 \mathrm{~V}$, and scaled using the extracted single-photon correlation as seen in Fig. 4 and Fig. 6(a)] is shown in Fig. 5, thus already scaled to the calibrated number of recorded photons pulse ${ }^{-1}$. The corresponding Poisson distribution with $\sigma_{\mathrm{p}}=\sqrt{80} \approx 9$ next to a Gaussian fit yielding $\sigma=11$ is shown, the latter indicating a roughly $20 \%$ additional contribution to the shot noise. This increase in the standard deviation of the experimental data is

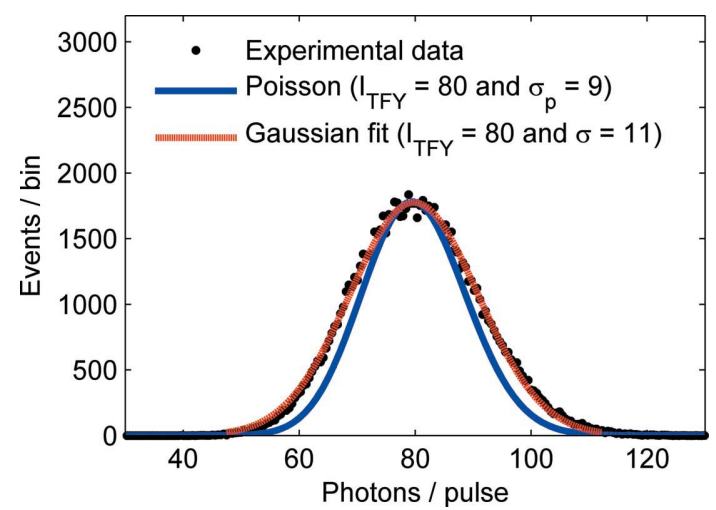

Figure 5

Pulse height distribution of the integrated APD single pulse intensity for $10^{5}$ X-ray pulses (black dots). A mean flux of 80 photons per pulse is derived, when scaling the measured signal to the values as derived in Fig. 4. A Poisson function with $I_{\mathrm{TFY}}=80$ (blue solid line) and Gaussian fit to the data with $\sigma=11$ (red dashed line) are shown for comparison. 
due to several factors which, amongst others, are: (i) the broadening of each single discrete photon peak as described above, (ii) in top-up mode not all 40/60 bunches are equally refilled at once, which effectively leads to charge fluctuations in individual electron bunches, which are larger than the 1\% top-up limit of the total (i.e. bunch-averaged) storage ring current. In summary, the result in Fig. 5 shows that we have a nearly shot-noise-limited detection scheme operational, where only less than $20 \%$ of the noise is accountable by electronic (and other systematic) noise contributions.

\subsection{Linearity of APD and dynamic range}

To assess the linear detector response over the entire dynamic range, we analyzed in detail the pulse height distributions of each integrated APD pulse (Fig. 4a). In the low-flux cases shown in Figs. 6(a), 6(c) and 6(e) the detector response is rather linear, independent of the bias voltage on the APD. In the high-flux distributions [Fig. $6(b), 6(d)$ and $6(f)$ ], the distributions clearly indicate a non-linear behaviour (slowly merging to saturation) at the larger bias voltages of 300 and $350 \mathrm{~V}$. Qualitatively this is due to a saturation of the integrated pre-amplifier within the APD head. In order to quantify the linear response regime of the APD as a function of the bias voltage, the mean APD signal as a function of incident X-ray intensity is plotted in Fig. 7. At the highest bias of $350 \mathrm{~V}$ the APD response is linear up to a mean signal of 20 photons, at $300 \mathrm{~V}$ bias further up to 40 photons and at $200 \mathrm{~V}$ bias up to at least 80 photons. In addition, these measurements also verify the linear response of the entire system up to these limits. Thus our setup is able to operate at total fluorescence yield count rates of up to 100 photons pulse ${ }^{-1}$ with single-photon sensitivity or $\gg 10^{8}$ photons $\mathrm{s}^{-1}$ when applied at PETRA III in 60-bunch mode. This also shows the dynamic range increase of two to three orders of magnitude compared with single-photon counting methods, where the count rates are limited to $\ll 1$ photon pulse ${ }^{-1}$.

\subsection{High signal quality for measuring a spin transition process: solvated $\left[\mathrm{Fe}^{\text {II }}(\mathrm{bpy})_{3}\right]^{2+}$}

As a benchmark experiment to compare the present DAQ scheme with previously reported TR-XAS measurements, we have chosen aqueous iron(II)-tris( $\left.2,2^{\prime}\right)$-bipyridine
APD bias $200 \mathrm{~V}$
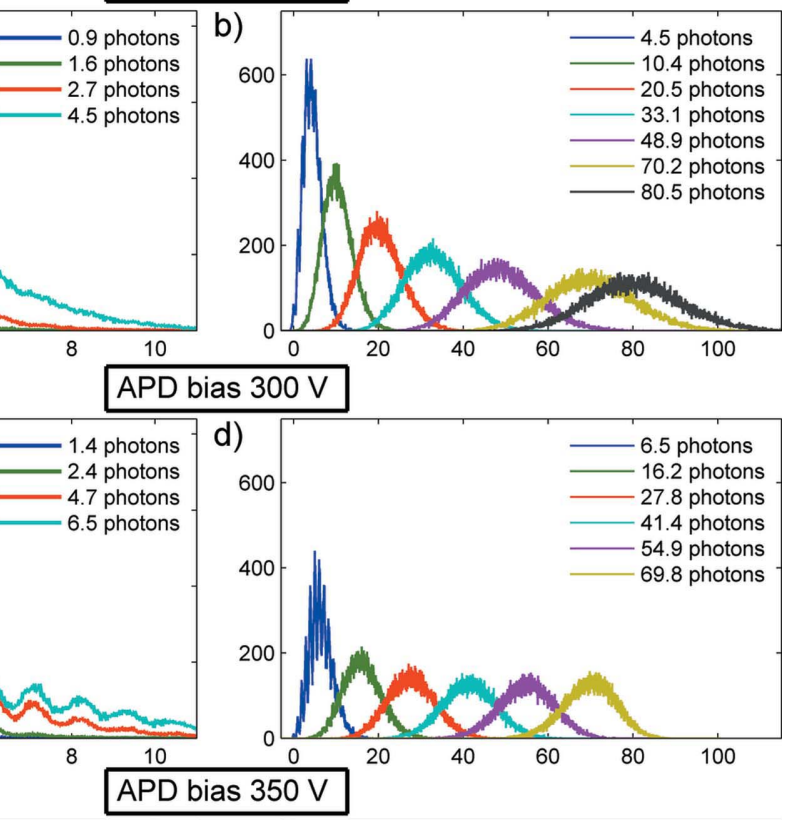

APD bias $350 \mathrm{~V}$



Figure 6

Integrated detector signal for a collection of single measurements (or pulse height distributions) for $350 \mathrm{~V}$ bias with low $(e)$ and high $(f)$ photon flux. The strong preamplifier gain amplifies the signal to its limiting value leading to the asymmetric pulse shape near 60 photons in $(f)$ (see also Fig. 7). 
$\left\{\left[\mathrm{FeII}(\mathrm{bpy})_{3}\right]^{2+}\right\}$ which has been readily studied using both low- and high-repetition optical laser pump/X-ray probe setups both at synchrotrons and XFELs (Milne et al., 2010; Bressler et al., 2009; Gawelda, Cannizzo et al., 2007; Cannizzo et al., 2010; Gawelda, Pham et al., 2007; Gawelda et al., 2009). Upon laser excitation with $515 \mathrm{~nm}$ light the system is excited from a low-spin (LS) ground state to a metal-to-ligand charge transfer (MLCT) excited state and subsequently relaxes (on a $100 \mathrm{fs}$ time scale) to a high-spin (HS) quintet state (Cannizzo et al., 2010). This LS to HS transition is accompanied by an $\mathrm{Fe}-\mathrm{N}$ bond elongation of $\sim 0.2 \AA$, giving rise to a fairly strong transient XANES signal. The HS state relaxes back to the LS ground state with a solvent-dependent lifetime, e.g. with $0.6 \mathrm{~ns}$ in $\mathrm{H}_{2} \mathrm{O}$ (Gawelda, Cannizzo et al., 2007) and $0.96 \mathrm{~ns}$ in $\mathrm{CH}_{3} \mathrm{CN}$ (Jamula et al., 2014). The changes in structure and spin states result in a change of the X-ray absorption spectrum and have been analysed via EXAFS (Gawelda, Pham et al., 2007) and XANES (Gawelda et al., 2009). We show TR XANES data during two different measurement campaigns: earlier results have been limited in signal quality due to software constraints, so only the raw digitized APD signal traces were recorded (Fig. 4a) and post-processed, but, more severely, the number of acquired pulses per data point was constrained to only a few tens of thousands (albeit the laser operated at $\mathrm{MHz}$ repetition rates). After software and hardware improvements our latest results not only reproduce the earlier data quality (when taking the dramatically different statistics into account) but facilitated nearly real-time data acquisition and pre-processing at $7.8 \mathrm{MHz}$ (60-bunch mode), which includes (i) baseline correction and integration of all signal traces, and (ii) averaging over several samples to deliver an average signal value $I_{\mathrm{TFY}}$ together with its standard deviation $\sigma$.

Fig. 8 shows the TR XANES of $\left[\mathrm{Fe}^{\mathrm{II}}(\mathrm{bpy})_{3}\right]^{2+}$ dissolved in $\mathrm{CH}_{3} \mathrm{CN}$, thus the ground state (laser-off), $\sim 100 \mathrm{ps}$ after photoexcitation (laser-on) and the resulting transient signal (difference). The average laser power measured at the sample position was $\sim 2 \mathrm{~W}$ at $1.3 \mathrm{MHz}$ repetition rate (thus a pulse energy of $\sim 1.5 \mu \mathrm{J}$ ), and the laser spot size $\sim 50 \mu \mathrm{m} \times 50 \mu \mathrm{m}$ (slightly larger than the X-ray spot size of $\sim 15 \mu \mathrm{m} \times 30 \mu \mathrm{m}$ ). The X-ray probe energy was scanned over a range of $50 \mathrm{eV}$ in

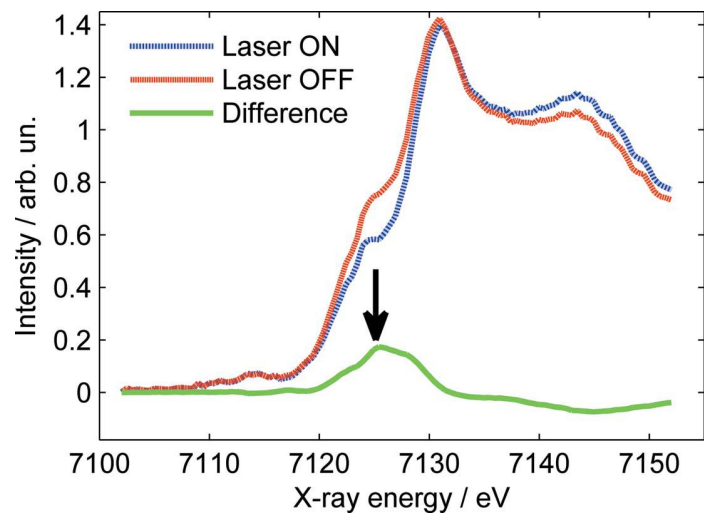

Figure 8

Time-resolved XANES scan without (blue dashed curve) and $100 \mathrm{ps}$ after (red dashed curve) laser excitation of photoexcited $\left[\mathrm{Fe}^{\mathrm{II}}(\mathrm{bpy})_{3}\right]^{2+} /$ acetonitrile together with its transient absorption signal (green curve).

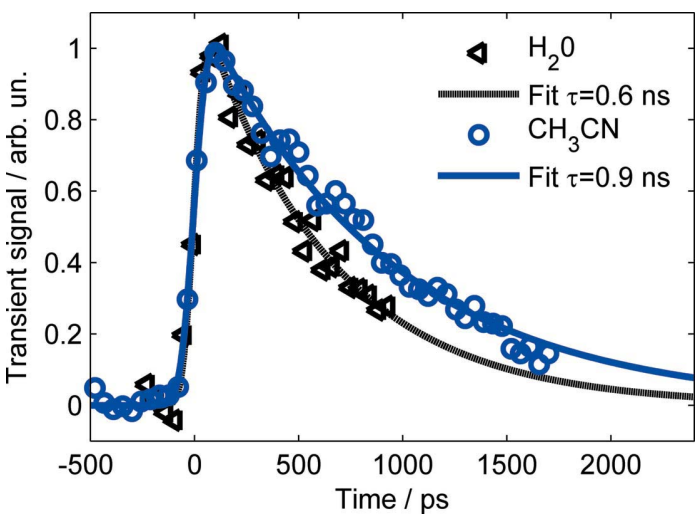

Figure 9

Time-delay scan of the transient signal of $\left[\mathrm{Fe}^{\mathrm{II}}(\mathrm{bpy})_{3}\right]^{2+}$ in $\mathrm{H}_{2} \mathrm{O}$ (black triangles) and $\mathrm{CH}_{3} \mathrm{CN}$ (blue circles) at $7125 \mathrm{eV}$ (arrow in Fig. 8), together with a fit of a Gaussian error function convoluted with a single exponential decay. The decay times of $0.6 \mathrm{~ns}$ in $\mathrm{H}_{2} \mathrm{O}$ (dotted black line) and $0.9 \mathrm{~ns}$ in $\mathrm{CH}_{3} \mathrm{CN}$ (solid blue line) agree with the literature data. The rise time of $0.1 \mathrm{~ns}$ is almost equivalent to the pulse duration of the $\mathrm{X}$-rays. The relatively low $\mathbf{S} / \mathrm{N}$ of $\sim 20$ is due to the fact that these spectra were recorded with relatively poor laser/X-ray overlap conditions (after these initial time-delay scans we usually optimize overlap conditions to achieve $\mathrm{S} / \mathrm{N}$ values as shown, for example, in Fig. 8).

$0.5 \mathrm{eV}$ steps (to cover the XANES region) with the collection time set to $1 \mathrm{~s}$ per data point. The excited-state fraction was determined by the amplitude of the transient signal (relative to the absorption edge jump) to $\sim 28 \%$ via comparison with prior measurements reported by Gawelda et al. (2009) and Gawelda, Pham et al. (2007).

The kinetics of the transient signal at its maximum value (7125 eV, or vertical arrow in Fig. 8) have been recorded via time-delay scans (in steps of 44.44 ps) for both solvents (Fig. 9). A convolution of a Gaussian error function with a single exponential decay has been fitted to the measured values, yielding a decay time of $0.6 \mathrm{~ns}$ in $\mathrm{H}_{2} \mathrm{O}$ and $0.9 \mathrm{~ns}$ in $\mathrm{CH}_{3} \mathrm{CN}$, both agreeing well with published values (Gawelda, Cannizzo et al., 2007; Jamula et al., 2014). A slight lifetime shortening for acetonitrile ( 0.9 versus $0.96 \mathrm{~ns}$ ) can be attributed to the higher temperature of the laser-heated solvent in this $\mathrm{MHz}$ pumpprobe experiment. The rise time of $0.1 \mathrm{~ns}$ corresponds to the X-ray pulse duration (the laser pulse width of $0.3 \mathrm{ps}$ does not contribute here) and no significant broadening of the rise time due to possible additional timing jitter between laser and $\mathrm{X}$-ray pulses is present.

In order to judge the performance of the current $\mathrm{MHz}$ scheme we compare the transient XANES spectra with different setups using $\mathrm{kHz}$ and $\mathrm{MHz}$ laser systems, with integrated detection scheme and SPC schemes (Fig. 10). With a $1 \mathrm{kHz}$ laser system and gated integrator scheme (Gawelda, Pham et al., 2007) an appreciable $\mathrm{S} / \mathrm{N}$ is achieved only after long measurement times [about $10 \mathrm{~h}$ in total; Fig. 10(a)]. With the present $\mathrm{MHz}$ DAQ scheme we already achieved with limited pulses $\left[2 \times 10^{5}\right.$; Fig. $\left.10(b)\right]$, or only $26 \mathrm{~ms}$ collection time per data point, only a roughly twofold worse $\mathrm{S} / \mathrm{N}$ ratio, which underscores the high potential of the current DAQ scheme. Fig. 10(c) shows the state-of-the-art for SPC at $1.3 \mathrm{MHz}$ pump-probe rate (thus after $35 \mathrm{~s}$ collection time per 
Table 2

Experimental laser excitation and X-ray probing parameters of the transient XANES shown in Figs. 10 and 11(a).

To compare the achievable $\mathrm{S} / \mathrm{N}$ with different DAQ schemes and laser excitation conditions the scaled experimental $\mathrm{S} / \mathrm{N}_{\text {scaled }}$ is calculated by normalization of the experimental S/N $\mathrm{N}_{\exp }$ to $\mathrm{S} / \mathrm{N}_{\text {scaled }} \dagger$ for identical conditions (here $S_{\max }=10 \%$ of the respective $K$-edge jump and $t_{\text {acq }}=1 \mathrm{~s}$ ).

\begin{tabular}{|c|c|c|c|c|c|}
\hline Sample & $\begin{array}{l}{\left[\mathrm{Fe}(\text { bpy })_{3}\right]^{2+} \text { in }} \\
\mathrm{H}_{2} \mathrm{O} \neq \text { (Fig. 10a) }\end{array}$ & $\begin{array}{l}{\left[\mathrm{Fe}(\text { bpy })_{3}\right]^{2+} \text { in }} \\
\mathrm{H}_{2} \mathrm{O} \text { (Fig. } 10 b \text { ) }\end{array}$ & $\begin{array}{l}{\left[\mathrm{Fe}(\text { terpy })_{2}\right]^{2+} \text { in }} \\
\mathrm{H}_{2} \mathrm{O} \uparrow \text { (Fig. } 10 c \text { ) }\end{array}$ & $\begin{array}{l}{\left[\mathrm{Fe}(\text { bpy })_{3}\right]^{2+} \text { in }} \\
\mathrm{CH}_{3} \mathrm{CN} \S \text { (Fig. } 10 d \text { ) }\end{array}$ & $\begin{array}{l}{\left[\mathrm{Co}(\mathrm{CN})_{6}\right]^{3+} \text { in }} \\
\mathrm{H}_{2} \mathrm{O} \$ \text { (Fig. 11) }\end{array}$ \\
\hline Beamline & Micro-XAS@SLS & P01@ PETRA III & 7ID-D @ APS & P01 @ PETRA III & P01@ PETRA III \\
\hline aser excitation wavelength & $0 \mathrm{~nm}$ & $15 \mathrm{~nm}$ & $532 \mathrm{~nm}$ & $515 \mathrm{~nm}$ & $257.5 \mathrm{~nm}$ \\
\hline Laser pulse energy & $\sim 200 \mu \mathrm{J}$ & $\sim 2 \mu \mathrm{J}$ & $\sim 2 \mu \mathrm{J}$ & $\sim 1.5 \mu \mathrm{J}$ & $<1 \mu \mathrm{J}$ \\
\hline Laser spot size $(\mathrm{V} \times \mathrm{H})$ & $\sim 300 \mu \mathrm{m} \times 300 \mu \mathrm{m}$ & $\sim 150 \mu \mathrm{m} \times 120 \mu \mathrm{m}$ & $<100 \mu \mathrm{m} \times 100 \mu \mathrm{m}$ & $\sim 50 \mu \mathrm{m} \times 50 \mu \mathrm{m}$ & $\sim 50 \mu \mathrm{m} \times 50 \mu \mathrm{m}$ \\
\hline petition rate & $2 \mathrm{kHz}$ & $7.8 \mathrm{MHz}$ & $6.5 \mathrm{MHz}$ & $5.2 \mathrm{MHz}$ & $7.8 \mathrm{MHz}$ \\
\hline $\mathrm{X}$-ray spot size $(\mathrm{V} \times \mathrm{H})$ & $100 \mu \mathrm{m} \times 260 \mu \mathrm{m}$ & $500 \mu \mathrm{m} \times 100 \mu \mathrm{m}$ & $\sim 8 \mu \mathrm{m} \times 7 \mu \mathrm{m}$ & $\sim 15 \mu \mathrm{m} \times 30 \mu \mathrm{m}$ & $\sim 15 \mu \mathrm{m} \times 30 \mu \mathrm{m}$ \\
\hline Maximum transient norm & $10 \%$ & $1.2 \%$ & $46 \%$ & $17 \%$ & $0.1 \%$ \\
\hline Acquisition time per energy point $t_{\mathrm{acq}}(\mathrm{s})$ & $\sim 100$ & 0.026 & 35 & $\sim 1$ & 2 \\
\hline Detected X-ray photons per pulse & $\sim 1$ & $\sim 50$ & $<0.1$ & $\sim 5$ & $\sim 100$ \\
\hline Calculated $\mathrm{S} / \mathrm{N}_{\text {theo }}$ at $S_{\max }$ & 28 & 18 & 750 & 450 & 15 \\
\hline $\mathrm{S} / \mathrm{N}_{\exp }$ at $S_{\max }$ & 23 & 9 & 550 & 350 & 10 \\
\hline
\end{tabular}

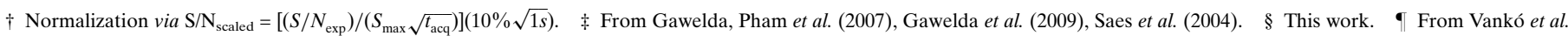

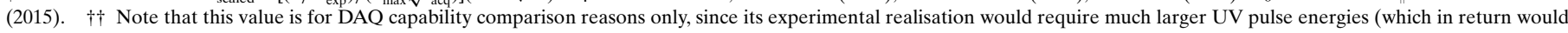

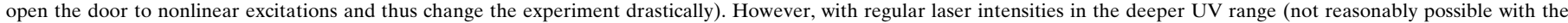
current laser system), where the sample exhibits a larger optical cross section, this $\mathrm{S} / \mathrm{N}$ could be realised, in principle.

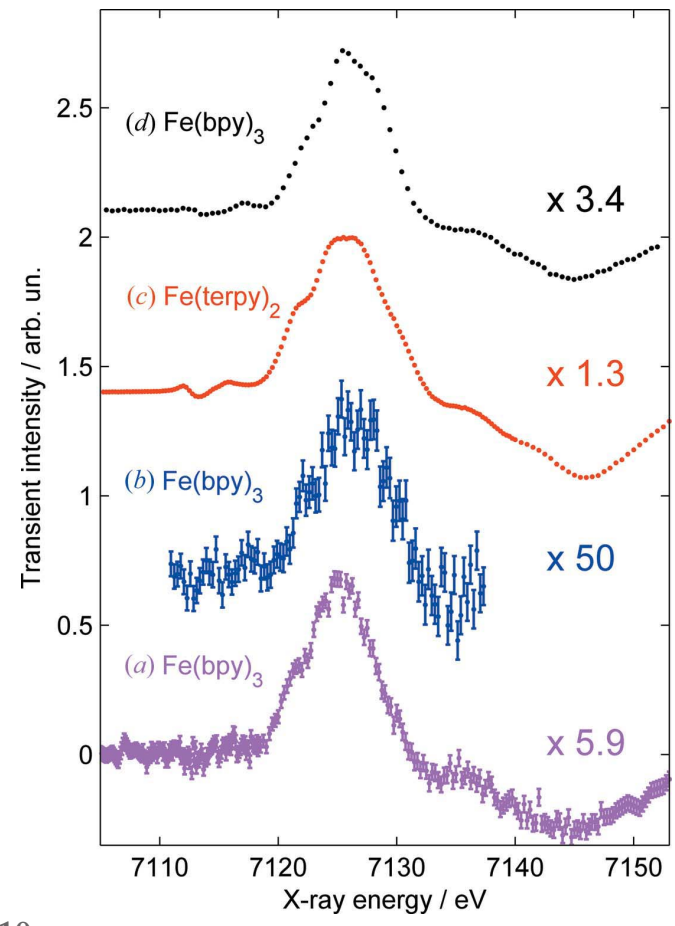

Figure 10

Comparison of different normalized transient XANES spectra. (a) Result using a $1 \mathrm{kHz}$ laser system with a total collection time of about $10 \mathrm{~h}$ (Gawelda et al., 2009). (b) Result with the current DAQ scheme, but averaging only $2 \times 10^{5}$ X-ray pulses per data point. $(c)$ Measurement of the similar $\left[\mathrm{Fe}^{\mathrm{II}}(\text { terpy })_{2}\right]^{2+}$ measured with a single-photon-counting DAQ scheme (Vankó et al., 2015). (d) Our recent measurement on $\left[\mathrm{Fe}^{\mathrm{II}}(\mathrm{bpy})_{3}\right]^{2+}$ using $\sim 5 \times 10^{6}$ pulses per data point (or only $\sim 1 \mathrm{~s}$ per data point).

data point) (Vankó et al., 2015), which is topped by our recent integrated detection scheme fof aqueous $\left[\mathrm{Fe}^{\mathrm{II}}(\mathrm{bpy})_{3}\right]^{2+}$, Fig. $10(d)\}$, recorded in $1 \mathrm{~s}$ per data point. The multiplication factors in Fig. 10 reflect the achieved excited-state population, which is only governed by the exciting laser source and the $\mathrm{X}$-ray/laser focusing conditions, and thus it does not depend on the utilized DAQ scheme. The $2.5 \times$ larger factor for the present study versus the SPC experiment at APS reflects the smaller focusing conditions at APS (which excite accordingly $2.5 \times$ more molecules), and is fully in line with our shot-noise analysis presented earlier (\$3). In order to compare these different experiments we have analyzed the achieved S/N. In this regard we define the experimental $\mathrm{S} / \mathrm{N}$ of the transient XANES spectrum (in Fig. 10) as the ratio $\mathrm{S} / \mathrm{N}_{\exp }=\left(S / \sigma_{\mathrm{S}}\right)$ of the transient absorption signal $S$ and its standard error $\sigma_{\mathrm{S}}$ at the energy where the transient XANES exhibits its maximum (absolute) value $S_{\max }$, e.g. in the case of $\left[\mathrm{Fe}^{\mathrm{II}}(\mathrm{bpy})_{3}\right]^{2+}$ at $7125 \mathrm{eV}$ (the maximum transient value in Fig. 10, or the vertical arrow in Fig. 8). We thus corrected each experiment for its different laser excitation condition, since these do not influence the capacity of the utilized DAQ scheme, but merely reflect the varying focusing (and thus laser fluence) conditions of the exciting laser source (together with the achievable $\mathrm{X}$-ray focus). The normalized conditions together with the relevant experimental parameters for each experimental scheme are summarized in Table 2. Interestingly, this comparison equally confirms that all these different DAQ schemes deliver very similar $\mathrm{S} / \mathrm{N}$ ratios (when normalizing their values to the expected ones, see Table 2): the $\left[\mathrm{Fe}^{\mathrm{II}}(\text { terpy })_{2}\right]^{2+}$ transient spectrum represents the current state-of-the-art S/N in TR XAS, and the comparison with our $\mathrm{MHz}$ measurement of $\left[\mathrm{Fe}^{\mathrm{II}}(\text { bpy })_{3}\right]^{2+}$ in $\mathrm{CH}_{3} \mathrm{CN}$ (Fig. 10d) shows that we have achieved a comparable signal quality, however, with 35 times less collection time per data point, agreeing with our expectations. SPC techniques (Fig. 10c) limit the detected flux to about 0.1 photons pulse ${ }^{-1}$ (to avoid pileup artifacts), while we detected about 5 photons pulse ${ }^{-1}$ (Fig. 10d), and together with the different excitation yields in 
both measurements we obtain nearly identical results, thus with better signal quality (in less time) with the current $\mathrm{MHz}$ DAQ scheme. Summarizing this collection in Table 2, in the last line we scaled $\mathrm{S} / \mathrm{N}_{\exp }$ to comparable values of transient signal $S_{\max }$ (thus correcting out the different excitation yields and maximum transient signal) together with the different data collection times. This allows the different DAQ schemes to be compared: the $1 \mathrm{kHz}$ experiment shows the lowest $\mathrm{S} /$ $\mathrm{N}_{\text {scaled }}$ with the MHz SPC method delivering about a ten times larger $\mathrm{S} / \mathrm{N}_{\text {scaled }}$, while the current $\mathrm{MHz}$ DAQ scheme delivered the largest $\mathrm{S} / \mathrm{N}_{\text {scaled }}$ under otherwise comparable experimental conditions. The up to $\sim 30$-fold increase from the $\mathrm{MHz}$ SPC experiment to the here-presented $\mathrm{MHz}$ DAQ scheme clearly reflects the $\sim 1000$-fold increase in counted photons pulse ${ }^{-1}$, leading to an increase of $\sqrt{1000}$ in $\mathrm{S} / \mathrm{N}$. We can also compare our representative single-scan XANES transient of $\left[\mathrm{Fe}^{\mathrm{II}}(\text { bpy })_{3}\right]^{2+}$ in Fig. 8 with a $\mathrm{S} / \mathrm{N}$ of 350 with the representative single XANES transient scan of the same molecule (Lima et al., 2011) with a $\mathrm{S} / \mathrm{N}$ of 45 . Our measurement presented here yields a factor $350 / 45 \simeq 7.8$ better $\mathrm{S} / \mathrm{N}$ which agrees nicely with the expected improvement of $\sqrt{62.4 / 1.2} \approx$ 7.2 from the ratio $62.4 / 1.2$ of useful flux between both sources (see Table 1). Furthermore, the dynamic range of an APD can in principle be boosted from $\sim 100$ to several thousand $\left(10^{3}\right)$ photons per pulse, as was demonstrated in the $\mathrm{kHz}$ experiment at SLS and ALS (Saes et al., 2004) measuring transient XAS signals in transmission mode, which provides ample room for even further improvement.

\subsection{TR XANES of weakly excited aqueous $\left[\mathrm{Co}(\mathrm{CN})_{6}\right]^{3+}$}

We further applied the implemented DAQ scheme to aqueous hexacyanocobaltate(III) $\left(\left[\mathrm{Co}(\mathrm{CN})_{6}\right]^{3+}\right)$. This sample exhibits two ligand field absorption bands around 260 and $310 \mathrm{~nm}$ (Scandola \& Scandola, 1971), and light excitation into these bands is followed by an intersystem crossing to a ligand field excited triplet state with a near-unit quantum yield (Nishazawa \& Ford, 1981). This triplet state has a lifetime of about $2.6 \mathrm{~ns}$ and decays back to the ground state (with a quantum yield of 0.69 ) or undergoes $(\mathrm{CN})^{-}$ligand detachment (with a yield of 0.31 ), and is promptly followed by association of a solvent water molecule (Milder et al., 1984). This system serves ideally as a challenging benchmark experiment as its molar absorptivity at $257.5 \mathrm{~nm}$ is only about $130 \mathrm{M}^{-1} \mathrm{~cm}^{-1}$, thus about 45 times smaller than that for $\left[\mathrm{Fe}(\text { bpy })_{3}\right]^{2+}$ in $\mathrm{H}_{2} \mathrm{O}$ at $515 \mathrm{~nm}$. The present $\left[\mathrm{Co}(\mathrm{CN})_{6}\right]^{3+}$ thus represents a sample with very low excitation yields. The details of the photocycle of this molecule will not be addressed in this publication; we will only use this sample to demonstrate the capabilities to measure small TR transient signals in fairly short data acquisition times.

We have measured TR XANES of a $100 \mathrm{~m} M$ aqueous solution of $\left[\mathrm{Co}(\mathrm{CN})_{6}\right]^{3+}$ after photoexcitation with $257.5 \mathrm{~nm}$ light (the fourth harmonic of our laser system) operating at 1.95 MHz, and probing in 40-bunch mode of PETRA III at 7.8 MHz. The XANES spectrum measured with an acquisition time of $2 \mathrm{~s}$ per energy point shows a very weak transient signal of about $1 / 1000$ of the $K$-edge-jump itself, but the $\mathrm{S} / \mathrm{N}$ is already $\sim 10$ (Fig. 11a). We have also compiled the relevant experimental parameters in Table 2, that show that the signal quality is very close to our expectations. Concerning the strategy to record all pulses at $7.8 \mathrm{MHz}$ while the laser-on $\mathrm{X}$-ray pulses arrive at $1.95 \mathrm{MHz}$ (or for every fourth X-ray pulse), this is nicely apparent from the statistically derived error bars for the groups of laser-on and laser-off data: the laser-on error bars are indeed $\sqrt{3}$ times larger than the laseroff error bars.

Equally important is to inspect the error bars on the transient data (difference between laser-on and laser-off data), derived from the on-board fast averaging process: the value of the error bars in the transient of Fig. 11(a) are squared and plotted in Fig. 11(b) for each energy point. It resembles very much the ground-state spectrum, which is indeed expected for a shot-noise-limited detection method. But one also observes occasional deviations (outliers) with larger values. These are due to the top-up operation mode of PETRA III, which is easily identified for this scan in Fig. 11(c): the blue curve shows

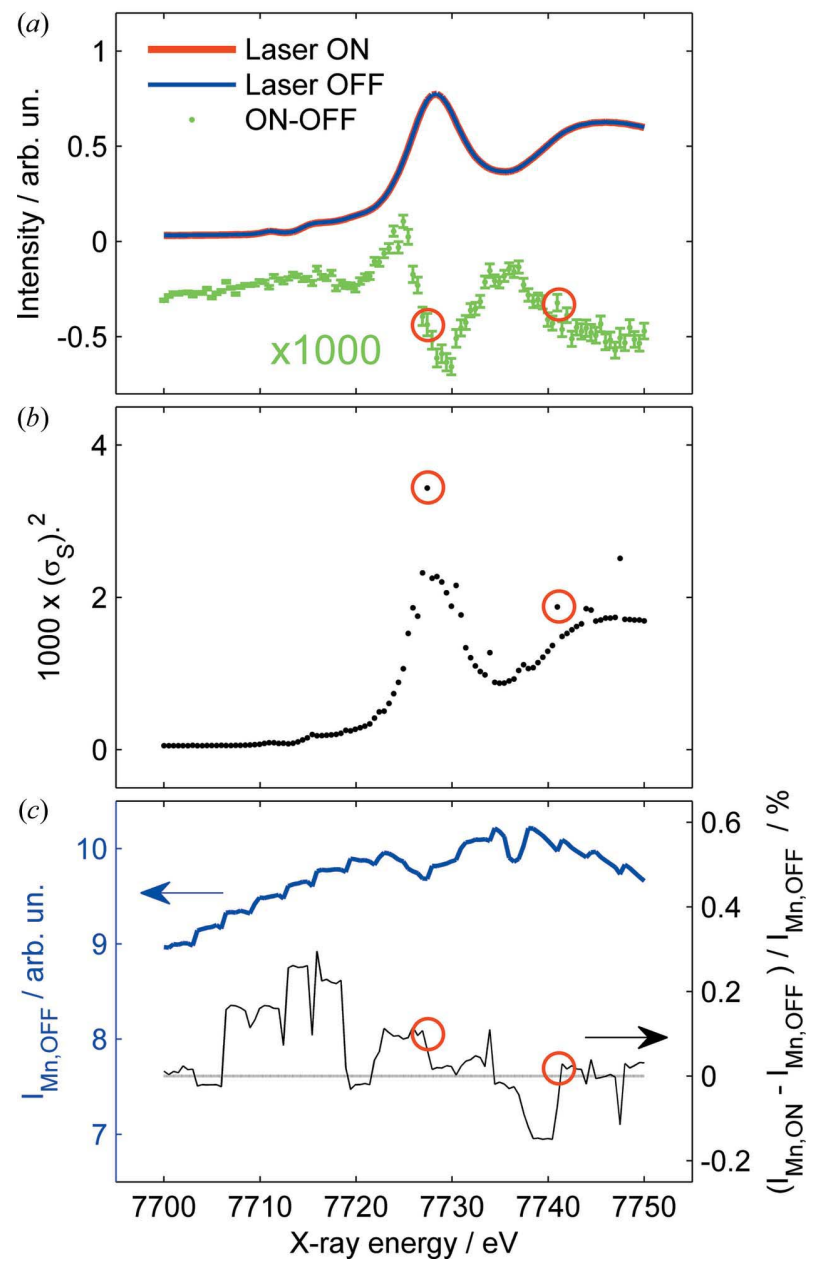

Figure 11

(a) XANES of $\left[\mathrm{Co}(\mathrm{CN})_{6}\right]^{3+}$ after $257.5 \mathrm{~nm}$ excitation. (b) Squared error bars of transient difference. (c) $I_{\mathrm{Mn}}$ measurement which is used as an $I_{0}$ measurement as well as the normalized difference between $I_{\mathrm{Mn}}$ for laser $\mathrm{ON}$ and OFF which shows the unbalanced top-up of electron bunches corresponding to laser $\mathrm{ON}$ and laser OFF. 
the measured fluorescence intensity from the Mn foil downstream of the sample, which we used for correcting the abrupt intensity changes in our measurement. Every time an injection occurs, the intensity into the beamline fluctuates for a few seconds. These fluctuations lead in turn to worse statistics in the MHz DAQ averaging, which nicely explains the increased error bar sizes. Two examples are marked by red circles in Fig. 11, but actually every single injection delivers such an increased error bar size, equally supporting the soundness of the implemented averaging scheme. It also helps to understand better the issues when filling a few bunches among the 40/60 stored bunches: some electron bunches are preferentially filled, and since we record the laser-on and laser-off data on alternating, and thus different, bunches, there is some probability that the groups of even or odd bunches are slightly preferentially filled. Fig. 11(c) shows this, when we divide the measured intensity on the laser-on bunches by those being used for the laser-off signal (and in the absence of any laserinduced effect). The intensity on each subgroup changes by up to $0.2 \%$ following each injection. This is substantially higher than the $0.1 \%$ transient difference signal which we desire to measure, but normalization takes care of these fluctuations.

\subsection{Discussion and outlook}

We have implemented a setup for TR XAS at the dynamics beamline P01 of PETRA III with two key components, which improve the data collection efficiency by a total of up to six orders of magnitude. The first one is a $\mathrm{MHz}$ fiber amplifier laser system with a $24 \mathrm{~W}$ average output power and an adjustable repetition rate from $400 \mathrm{kHz}$ to $15.6 \mathrm{MHz}$ synchronized to the RF frequency of the PETRA III storage ring. Compared with a traditional $\mathrm{kHz} \mathrm{Ti}: \mathrm{Sa}$ laser system this allows for a thousand-fold faster acquisition of laser-excited XAS data in TFY mode. The second element is a MHz DAQ system developed at European XFEL, which acts similar to a gated integrator, but operates, in principle, up to the full RF of PETRA III $(500 \mathrm{MHz})$. Here we recorded X-ray spectra by averaging typically $\sim 10^{7}$ shots at $7.8 \mathrm{MHz}$, which were presorted according to laser-on and laser-off conditions. The APD signal traces were sampled with $2 \mathrm{GS} \mathrm{s}^{-1}$ (and 12-bit) over the APD pulse trace and the integration algorithm delivered a reliable measure of each integrated single pulse intensity. We have confirmed the linear operation of the entire DAQ scheme and furthermore characterized in detail the linear working regimes of the APD as a function of the bias voltage. These measurements exploit the increased dynamic range of this setup compared with standard single-photon-counting techniques by about three orders of magnitude; overall, we can achieve total fluorescence yield count rates up to 100 photons pulse ${ }^{-1}$ or $\gg 10^{8}$ photons s $^{-1}$ at PETRA III in 60-bunch mode. Currently the limitation to measure even higher photon numbers ( $\gg 100$ photons pulse ${ }^{-1}$ ) with our commercially pre-amplified APD is related to its fixed large pre-amplifier gain and will be eliminated in the near-term by implementing a switchable gain preamplifier. At even higher photon fluxes (exceeding $10^{4}$ photons pulse ${ }^{-1}$ ) the APD without pre-amplifier should be able to reliably operate, and we also use the internal APD gain (driven by the bias voltage) to fine-tune the output trace to the desired voltage level on the ADC input. This will enable the setup to be used at powerful $\mathrm{X}$-ray free-electron lasers, such as the European X-ray Free Electron laser, which delivers even larger X-ray intensities $\left(10^{12}\right.$ photons pulse $\left.{ }^{-1}\right)$ at $4.5 \mathrm{MHz}$, thus conveniently within the specifications of the current setup.

Last but not least we have measured TR XANES spectra with quasi static $\mathrm{S} / \mathrm{N}$ of Fe-based spin transition systems next to a weakly (UV light) absorbing Co complex. Comparing the measurements of the MHz DAQ with those of a SPC DAQ scheme shows that we can effectively decrease acquisition times by a factor of 500 or acquire accordingly better TR signals at equivalent acquisition times, which is quantitatively fully in line with the corresponding reduced SPC intensity. One next step will be to make use of the significant decrease in acquisition time, e.g. for measuring TR XAS of samples undergoing non-reversible dynamical changes. The increase in $\mathrm{S} / \mathrm{N}$ ratio will allow measuring TR XAS with very small changes thus improving the sensitivity to even smaller lightinduced electronic and structural changes. Furthermore, we will be able to measure transients with very small excited-state fractions, allowing for decreased laser excitation energies, thus performing 'tickle-and-probe' experiments under the same laser excitation conditions used in laser-only pump-probe experiments. Just recently, this setup has been complemented by a multicrystal dispersive von Hamos X-ray emission spectrometer similar to a previously published one (Alonso-Mori et al., 2012), which utilizes the MHz pump-probe scheme to collect high-quality TR X-ray emission spectra as done by Vankó et al. (2010, 2013).

\section{Acknowledgements}

This work is financed by the European XFEL by the Deutsche Forschungsgemeinschaft (DFG) via SFB 925 (project A4), and by the Hamburg Centre for Ultrafast Imaging (CUI). The present $\mathrm{MHz}$ DAQ scheme was conceived by Christopher Youngman from European XFEL, who equally engaged in its first vital realisation steps. We thank Hans-Christian Wille for advice in using APD detectors, Frank-Uwe Dill for help during the setup of this experiment, Maria Teresa Nunez Pardo de Vera and Andre Rothkirch for vital help debugging software issues, and Dennis Görries and Alke Meents for fruitful discussions. AB acknowledges support from the International Max Planck Research School for Ultrafast Imaging and Structural Dynamics (IMPRS-UFAST), and we acknowledge the European Cluster of Advanced Laser Light Sources (EUCALL) within work packages PUCCA (CB) and UFDAC (PG), which has received funding from the European Union's Horizon 2020 research and innovation programme under grant agreement No 654220. Unless otherwise stated, all figures are copyright by the authors under the terms of the Creative Commons Attribution 4.0 International License. To view a copy of this license, visit http://creativecommons.org/ 
licenses/by/4.0/ or send a letter to Creative Commons, PO Box 1866, Mountain View, CA 94042, USA.

\section{References}

Alonso-Mori, R., Kern, J., Sokaras, D., Weng, T. C., Nordlund, D., Tran, R., Montanez, P., Delor, J., Yachandra, V. K., Yano, J. \& Bergmann, U. (2012). Rev. Sci. Instrum. 83, 073114.

ALS (2015). Advanced Light Source Storage Ring Parameters, https:// www-als.lbl.gov/index.php/beamlines/storage-ring-parameters. html.

Altarelli, M., Brinkmann, R., Chergui, M., Decking, W., Dobson, B., Düsterer, S., Grübel, G., Graeff, W., Graafsma, H., Janos Hajdu, Jonathan Marangos, J. P., Redlin, H., Riley, D., Robinson, I., Rossbach, J., Schwarz, A., Tiedtke, K., Tschentscher, T., Vartaniants, I., Wabnitz, H., Weise, H., Wichmann, R., Karl Witte, A. W., Wulff, M. \& Yurkov, M. (2006). The European X-ray Free-Electron Laser. Technical Design Report DESY 2006-097, pp. 1-26. DESY, Hamburg, Germany.

Baron, A. Q. R., Kishimoto, S., Morse, J. \& Rigal, J.-M. (2006). J. Synchrotron Rad. 13, 131-142.

Bergmann, U., Di Cicco, A., Wernet, P., Principi, E., Glatzel, P. \& Nilsson, A. (2007). J. Chem. Phys. 127, 174504.

Bergmann, U., Glatzel, P. \& Cramer, S. (2002). Microchem. J. 71, $221-$ 230.

Borland, M., Decker, G., Emery, L., Guo, W., Harkay, K., Sajaev, V. \& Yao, C.-Y. (2010). APS Storage Ring Parameters, http:// www.aps.anl.gov/Accelerator_Systems_Division/Accelerator_Oper ations_Physics/SRparameters/SRparameters.html.

Bressler, C. \& Chergui, M. (2004). Chem. Rev. 104, 1781-1812.

Bressler, C., Gawelda, W., Galler, A., Nielsen, M. M., Sundström, V., Doumy, G., March, A. M., Southworth, S. H., Young, L. \& Vankó, G. (2014). Faraday Discuss. 171, 169-178.

Bressler, C., Milne, C. J., Pham, V.-T., ElNahhas, A., van der Veen, R. M., Gawelda, W., Johnson, S. L., Beaud, P., Grolimund, D., Kaiser, M., Borca, C. N., Ingold, G., Abela, R. \& Chergui, M. (2009). Science, 323, 489-492.

Bressler, C., Saes, M., Chergui, M., Abela, R. \& Pattison, P. (2001). Nucl. Instrum. Methods Phys. Res. A, 467-468, 1444-1446.

Cannizzo, A., Milne, C. J., Consani, C., Gawelda, W., Bressler, Ch., van Mourik, F. \& Chergui, M. (2010). Coord. Chem. Rev. 254, 26772686.

Canton, S., Zhang, X., Zhang, J., van Driel, T. B., Kjaer, K. S., Haldrup, K., Chabera, P., Harlang, T., Suarez-Alcantara, K., Liu, Y., Pérez, J., Bordage, A., Pápai, M., Vankó, G., Jennings, G., Kurtz, C. A., Rovezzi, M., Glatzel, P., Smolentsev, G., Uhlig, J., Dohn, A. O., Christensen, M., Galler, A., Gawelda, W., Bressler, C., Lemke, H. T., Møller, K. B., Nielsen, M. M., Lomoth, R., Wärnmark, K. \& Sundström, V. (2013). J. Phys. Chem. Lett. 4, 1972-1976.

Chen, L. X., Jäger, W. J., Jennings, G., Gosztola, D. J., Munkholm, A. \& Hessler, J. P. (2001). Science, 292, 262-264.

ESRF (2015). ESRF Machine Parameters, http://www.esrf.eu/Users AndScience/Publications/Highlights/2006/XRS/XRS01.

FMB Oxford (2009). FMB Oxford Datasheet, Version 1, August 2009. FMB Oxford, Oxford, UK.

Feikes, J., von Hartrott, M., Wüstefeld, G., Hoehl, A., Klein, R., Müller, R. \& Ulm, G. (2009). Proceedings of the 23rd Particle Accelerator Conference (PAC09), Vancouver, BC, Canada.

Fister, T. T., Nagle, K. P., Vila, F. D., Seidler, G. T., Hamner, C., Cross, J. O. \& Rehr, J. J. (2009). Phys. Rev. B, 79, 174117.

Gawelda, W., Bressler, C., Saes, M., Kaiser, M., Tarnovsky, A., Grolimund, D., Johnson, S. L., Abela, R. \& Chergui, M. (2005). Phys. Scr. T115, 102-106.

Gawelda, W., Cannizzo, A., Pham, V.-T., van Mourik, F., Bressler, C. \& Chergui, M. (2007). J. Am. Chem. Soc. 129, 8199-8206.
Gawelda, W., Pham, V.-T., Benfatto, M., Zaushitsyn, Y., Kaiser, M., Grolimund, D., Johnson, S., Abela, R., Hauser, A., Bressler, C. \& Chergui, M. (2007). Phys. Rev. Lett. 98, 057401.

Gawelda, W., Pham, V.-T., van der Veen, R. M., Grolimund, D., Abela, R., Chergui, M. \& Bressler, C. (2009). J. Chem. Phys. 130, 124520.

Goeries, D., Dicke, B., Roedig, P., Stübe, N., Meyer, J., Galler, A., Gawelda, W., Britz, A., Geßler, P., Sotoudi Namin, H., Beckmann, A., Schlie, M., Warmer, M., Naumova, M., Bressler, C., Rübhausen, M., Weckert, E. \& Meents, A. (2016). Rev. Sci. Instrum. 87, 053116. Haldrup, K., Vankó, G., Gawelda, W., Galler, A., Doumy, G., March, A. M., Kanter, E. P., Bordage, A., Dohn, A., van Driel, T. B., Kjaer, K. S., Lemke, H. T., Canton, S. E., Uhlig, J., Sundström, V., Young, L., Southworth, S. H., Nielsen, M. M. \& Bressler, C. (2012). J. Phys. Chem. A, 116, 9878-9887.

Heimann, P. A., Lindenberg, A. M., Kang, I., Johnson, S., Missalla, T., Chang, Z., Falcone, R. W., Schoenlein, R. W., Glover, T. E. \& Padmore, H. A. (2001). Nucl. Instrum. Methods Phys. Res. A, 467468, 986-989.

Ibrahimkutty, S., Issenmann, D., Schleef, S., Müller, A.-S., Mathis, Y.-L., Gasharova, B., Huttel, E., Steininger, R., Göttlicher, J., Baumbach, T., Bartels, A., Janke, C. \& Plech, A. (2011). J. Synchrotron Rad. 18, 539-545.

Issenmann, D., Ibrahimkutty, S., Steininger, R., Göttlicher, J., Baumbach, T., Hiller, N., Müller, A.-S. \& Plech, A. (2013). J. Phys. Conf. Ser. 425, 092007.

Jaklevic, J., Kirby, J. A., Klein, M. P., Robertson, A. S., Brown, G. S. \& Eisenberger, P. (1977). Solid State Commun. 23, 679-682.

Jamula, L. L., Brown, A. M., Guo, D. \& McCusker, J. K. (2014). Inorg. Chem. 53, 15-17.

Ketenoglu, D., Harder, M., Klementiev, K., Upton, M., Taherkhani, M., Spiwek, M., Dill, F.-U., Wille, H.-C. \& Yavaş, H. (2015). J. Synchrotron Rad. 22, 961-967.

Krisch, M. \& Sette, F. (2002). Surf. Rev. Lett. 09, 969-976.

Larsson, J., Heimann, P. A., Lindenberg, A. M., Schuck, P. J., Bucksbaum, P. H., Lee, R. W., Padmore, H. A., Wark, J. S. \& Falcone, R. W. (1998). Appl. Phys. Mater. Sci. Process. 66, 587-591. Lima, F., Milne, C. J., Amarasinghe, D. C. V., Rittmann-Frank, M. H., van der Veen, R. M., Reinhard, M., Pham, V., Karlsson, S., Johnson, S. L., Grolimund, D., Borca, C., Huthwelker, T., Janousch, M., van Mourik, F., Abela, R. \& Chergui, M. (2011). Rev. Sci. Instrum. 82, 063111.

Lindenberg, A., Kang, I., Johnson, S., Missalla, T., Heimann, P., Chang, Z., Larsson, J., Bucksbaum, P., Kapteyn, H., Padmore, H., Lee, R., Wark, J. \& Falcone, R. (2000). Phys. Rev. Lett. 84, 111114.

March, A. M., Assefa, T. A., Bressler, C., Doumy, G., Galler, A., Gawelda, W., Kanter, E. P., Németh, Z., Pápai, M., Southworth, S. H., Young, L. \& Vankó, G. (2015). J. Phys. Chem. C, 119, 1457114578.

March, A. M., Stickrath, A., Doumy, G., Kanter, E. P., Krässig, B., Southworth, S. H., Attenkofer, K., Kurtz, C., Chen, L. X. \& Young, L. (2011). Rev. Sci. Instrum. 82, 073110.

Milder, S. J., Gray, H. B. \& Miskowski, V. M. (1984). J. Am. Chem. Soc. 106, 3764-3767.

Milne, C., Pham, V., Gawelda, W., Nahhas, A. E., van der Veen, R. M., Johnson, S. L., Beaud, P., Ingold, G., Borca, C., Grolimund, D., Abela, R., Chergui, M. \& Bressler, Ch. (2010). Acta Phys. Pol. A, 117, 391-393.

Navirian, H., Shayduk, R., Leitenberger, W., Goldshteyn, J., Gaal, P. \& Bargheer, M. (2012). Rev. Sci. Instrum. 83, 063303.

Neutze, R., Wouts, R., Techert, S., Davidsson, J., Kocsis, M., Kirrander, A., Schotte, F. \& Wulff, M. (2001). Phys. Rev. Lett. 87, 195508.

Nishazawa, M. \& Ford, P. C. (1981). Inorg. Chem. 20, 294-295.

PETRA III (2015). Machine Parameters PETRA III (Design Values), http://photon-science.desy.de/facilities/petra_iii/machine/param eters/index_eng.html. 
Reusch, T., Osterhoff, M., Agricola, J. \& Salditt, T. (2014). J. Synchrotron Rad. 21, 708-715.

Röhlsberger, R., Wille, H.-C., Schlage, K. \& Sahoo, B. (2012). Nature (London), 482, 199-203.

Saes, M., Bressler, C., Abela, R., Grolimund, D., Johnson, S., Heimann, P. \& Chergui, M. (2003). Phys. Rev. Lett. 90, 047403.

Saes, M., Gawelda, W., Kaiser, M., Tarnovsky, A., Bressler, C., Chergui, M., Johnson, S. L., Grolimund, D. \& Abela, R. (2003). Synchrotron Radiat. News. 16, 12-20.

Saes, M., van Mourik, F., Gawelda, W., Kaiser, M., Chergui, M., Bressler, C., Grolimund, D., Abela, R., Glover, T. E., Heimann, P. A., Schoenlein, R. W., Johnson, S. L., Lindenberg, A. M. \& Falcone, R. W. (2004). Rev. Sci. Instrum. 75, 24.

Sahle, Ch. J., Mirone, A., Niskanen, J., Inkinen, J., Krisch, M. \& Huotari, S. (2015). J. Synchrotron Rad. 22, 400-409.

Scandola, M. A. \& Scandola, F. (1971). J. Am. Chem. Soc. 2589, 18051810.

Schotte, F., Lim, M., Jackson, T., Smirnov, A. V., Soman, J., Olson, J. S., Phillips, G. N., Wulff, M. \& Anfinrud, P. A. (2003). Science, 300, 1944-1947.

Schröder, H.-C., Affeldt, A., Gausepohl, H.-P., Kub, G. \& Prieb, G. (2011). Proceedings of the 10th European Workshop on Beam Diagnostics and Instrumentation for Particle Accelerators (DIPAC 2011), Hamburg, Germany.

Smolentsev, G. \& Sundström, V. (2015). Coord. Chem. Rev. 304-305, $117-132$.

Soleil (2015). Soleil Sources and Accelerators, http://www. synchrotron-soleil.Fr/portal/page/portal/SourceAccelerateur.

Stamm, C., Kachel, T., Pontius, N., Mitzner, R., Quast, T., Holldack, K., Khan, S., Lupulescu, C., Aziz, E. F., Wietstruk, M., Dürr, H. A. \& Eberhardt, W. (2007). Nat. Mater. 6, 740-743.

Stebel, L., Malvestuto, M., Capogrosso, V., Sigalotti, P., Ressel, B., Bondino, F., Magnano, E., Cautero, G. \& Parmigiani, F. (2011). Rev. Sci. Instrum. 82, 123109.

Stern, E. A., Brewe, D. L., Beck, K. M., Heald, S. M. \& Feng, Y. (2005). Phys. Scr. T115, 1044-1046.
Sternemann, C., Sternemann, H., Huotari, S., Lehmkühler, F., Tolan, M. \& Tse, J. S. (2008). J. Anal. At. Spectrom. 23, 807.

Thompson, A., Attwood, D., Gulliksen, E., Howells, M., Kim, K.-J., Kirz, J., Kortright, J., Lindau, I., Liu, Y., Pianetta, P., Robinson, A., Scofield, J., Underwood, J., Williams, G. \& Winick, H. (2009). X-ray Data Booklet. Lawrence Berkeley National Laboratory, Berkeley, CA, USA.

Vankó, G., Bordage, A., Glatzel, P., Gallo, E., Rovezzi, M., Gawelda, W., Galler, A., Bressler, C., Doumy, G., March, A. M., Kanter, E. P., Young, L., Southworth, S. H., Canton, S. E., Uhlig, J., Smolentsev, G., Sundström, V., Haldrup, K., van Driel, T. B., Nielsen, M. M., Kjaer, K. S. \& Lemke, H. T. (2013). J. Electron Spectrosc. Relat. Phenom. 188, 166-171.

Vankó, G., Bordage, A., Pápai, M., Haldrup, K., Glatzel, P., March, A. M., Doumy, G., Britz, A., Galler, A., Assefa, T. A., Cabaret, D., Juhin, A., van Driel, T. B., Kjaer, K. S., Dohn, A. O., Møller, K. B., Lemke, H. T., Gallo, E., Rovezzi, M., Németh, Z., Rozsályi, E., Rozgonyi, T., Uhlig, J., Sundström, V., Nielsen, M. M., Young, L., Southworth, S. H., Bressler, C. \& Gawelda, W. (2015). J. Phys. Chem. C, 119, 5888-5902.

Vankó, G., Glatzel, P., Pham, V.-T., Abela, R., Grolimund, D., Borca, C. N., Johnson, S. L., Milne, C. J. \& Bressler, C. (2010). Angew. Chem. Int. Ed. 49, 5910-5912.

Vankó, G., Neisius, T., Molnár, G., Renz, F., KÁRPáti, S., Shukla, A. \& de Groot, F. M. F. (2006). J. Phys. Chem. B, 110, 1164711653.

Wille, H.-C., Franz, H., Röhlsberger, R., Caliebe, W. \& Dill, F. (2010). J. Phys. Conf. Ser. 217, 012008.

Wulff, M., Schotte, F., Naylor, G., Bourgeois, D., Moffat, K. \& Mourou, G. (1997). Nucl. Instrum. Methods Phys. Res. A, 398, 6984.

Zaouter, Y., Boullet, J., Mottay, E. \& Cormier, E. (2008). Opt. Lett. 33, 1527-1529.

Zhang, X., Lawson Daku, M. L., Zhang, J., Suarez-Alcantara, K., Jennings, G., Kurtz, C. A. \& Canton, S. E. (2015). J. Phys. Chem. C, 119, 3312-3321. 